
\title{
25 Research Suare \\ Rare malbranchea-like fungal isolates from clinical specimens in United States of America.
}

\section{Ernesto Rodríguez-Andrade}

Universitat Rovira i Virgili Facultat de Medicina I Ciences de la Salut

Jose F. Cano-Lira ( $\sim$ jose.cano@urv.cat)

Universitat Rovira i Virgili Facultat de Medicina I Ciences de la Salut https://orcid.org/0000-0003-4495-4394

Nathan Wiederhold

UTHSC at San Antonio: The University of Texas Health Science Center at San Antonio

\section{Alba Perez-Cantero}

Universitat Rovira i Virgili Facultat de Medicina I Ciences de la Salut

Josep Guarro

Universitat Rovira i Virgili Facultat de Medicina I Ciences de la Salut

Alberto M. Stchigel

Universitat Rovira i Virgili Facultat de Medicina I Ciences de la Salut

\section{Research}

Keywords: Antifungals, Arachnomycetales, Auxarthron, Clinical fungi, Malbranchea, Onygenales, Taxonomic novelties

Posted Date: February 23rd, 2021

DOI: https://doi.org/10.21203/rs.3.rs-255406/v1

License: @) (i) This work is licensed under a Creative Commons Attribution 4.0 International License. Read Full License 


\section{Abstract}

The fungi of the order Onygenales can cause important human infections; however, their taxonomy and worldwide occurrence is still little known. We have studied and identified a representative number of clinical fungi belonging to that order from a reference laboratory in the USA. A total of twenty-two strains isolated from respiratory tract (40\%) and human skin and nails (27.2\%) showed a malbranchea-like morphology. Six genera were phenotypically and molecularly identified, i.e. Auxarthron/Malbranchea (68.2 \%), Arachnomyces (9.1\%), Spiromastigoides (9.1\%), and Currahmyces (4.5\%), and two newly proposed genera (4.5\% each). Based on the results of the phylogenetic study, we synonymysed Auxarthron to Malbranchea, and erected two new genera: Pseudoarthropsis and Pseudomalbranchea. New species are proposed: Arachnomyces bostrychodes, A. graciliformis, Currahmyces sparsispora, Malbranchea gymnoascoidea, M. multiseptata, M. stricta, Pseudoarthropsis crassispora, Pseudomalbranchea gemmata and Spiromastigoides geomyces, along with a new combination for Malbranchea gypsea. The echinocandins showed the highest in vitro antifungal activity against the studied isolates, followed by terbinafine and posaconazole; in contrast, amphotericin B, fluconazole, itraconazole and 5-fluorocytosine were less active or lacked in vitro activity against these fungi.

\section{Taxonomic Novelties}

new genera: Pseudoarthropsis Stchigel, Rodr.-Andr. \& Cano, Pseudomalbranchea Rodr.-Andr., Cano \& Stchigel; new species: Arachnomyces bostrychodes Rodr.-Andr., Cano \& Stchigel, Arachnomyces graciliformis Rodr.-Andr., Stchigel and Cano, Currahmyces sparsispora Rodr.-Andr., Cano \& Stchigel, Malbranchea gymnoascoidea Rodr.-Andr., Stchigel \& Cano, Malbranchea multiseptata Rodr.-Andr., Cano \& Stchigel, Malbranchea stricta Rodr.-Andr., Stchigel \& Cano, Pseudoathropsis crassispora Rodr.-Andr., Stchigel \& Cano, Pseudomalbranchea gemmata Rodr.-Andr., Cano \& Stchigel, Spiromastigoides geomyces Stchigel, Rodr.-Andr. \& Cano; new combinations: Malbranchea californiense (G.F. Orr \& Kuehn) Rodr.-Andr., Stchigel \& Cano, Malbranchea chlamydospora (M. Solé, Cano \& Guarro) Rodr.-Andr., Cano \& Stchigel, Malbranchea compacta (G.F. Orr \& Plunkett) Rodr.-Andr., Cano \& Stchigel, Malbranchea concentrica (M. Solé, Cano \& Guarro) Rodr.-Andr., Stchigel \& Cano, Malbranchea conjugata (Kuehn) Rodr.-Andr., Cano \& Stchigel, Malbranchea indica (Kuehn) Rodr.-Andr., Cano \& Stchigel, Malbranchea longispora (Stchigel, Y. Marín, Guarro \& Cano) Rodr.-Andr., Stchigel \& Cano, Malbranchea ostraviense (Hubka, Dobiášová \& M. Kolař́́k) Rodr.-Andr., Cano \& Stchigel, Malbranchea pseudauxarthron (G.F. Orr \& Kuehn) Rodr.-Andr., Stchigel \& Cano, Malbranchea reticulata (Arx) Rodr.-Andr., Stchigel \& Cano, Malbranchea umbrina (Boud.) Rodr.-Andr., Cano \& Stchigel, Malbranchea zuffiana (Morini) Rodr.-Andr., Stchigel \& Cano, Pseudoarthropsis cirrhata (Oorschot \& de Hoog) Stchigel, Rodr.-Andr. \& Cano, Spiromastigoides gypsea (Sigler \& Carmichael) Stchigel, Rodr.-Andr. \& Cano.

\section{Introduction}

The order Onygenales includes medically important fungi, such as the dermatophytes and the thermally dimorphic systemic pathogens (Histoplasma, Coccidioides and related fungi), which are naturally present in keratinous substrates, in soil, and in freshwater sediments (Currah 1985, 1994, Doveri et al. 2012, Dukik et al. 2017, Hubálek 2000, Hubka et al. 2013, Sharma \& Shouche 2019). The genus Malbranchea, which is characterized by the production of alternate arthroconidia in branches from the vegetative hyphae, is one of the genus-form of this order; however, it's pathogenic role in human infections is little known. Only a few cases of fungal infections by species of this genus have been described: Malbranchea dendritica has been recovered from lungs, spleen and liver of mice (Sigler \& Carmichael 1976), Malbranchea pulchella has been suggested as a possible cause of sinusitis (Benda \& Corey 1994), and Malbranchea cinnamomea was recovered from dystrophic nails in patients with underlying 
chronic illnesses (Lyskova 2007, Salar \& Aneja 2007). More recently, Malbranchea spp. have been proposed as one of the causative agents of Majocchi's granuloma (Govind et al. 2017; Durdu et al. 2019). In a study of 245 patients with fungal saprophytic infections of nails and skin, Malbranchea spp. were isolated in $1 \%$ of skin samples (Lyskova 2007). Other studies demonstrated the coexistence (0.3\% of the cases) of Malbranchea spp. with the primary pathogen patients with tuberculosis (Benda \& Corey 1994, Yahaya et al. 2015).

Malbranchea was erected by Saccardo in 1882 for a single species, Malbranchea pulchella. It is characterized by alternate arthroconidia originat in curved branches from the vegetative hyphae, which developed on the surface of wet cardboard collected by A. Malbranche in Normandy, France (Fig. 1). Cooney and Emerson reviewed the genus in 1964, providing an appropriated description for mesophilic (M. pulchella) and thermophilic (Malbranchea sulfurea) species. In a more recent revision by Sigler and Carmichael (1976) twelve species were accepted, while a close relationship with the genus Auxarthron (family Onygenaceae, order Onygenales) was reported, i.e. the species Auxarthron conjugatum forms a malbranchea-like asexual morph, and Malbranchea albolutea produces a sexual morph related to Auxarthron. Also, Sigler and co-workers (2002) connected Malbranchea filamentosa with Auxarthron based on molecular studies, and also reported the production of fertile ascomata after an in vitro mating of several sexually compatible strains of $M$. filamentosa. The genus Auxarthron produces reddish brown, appendaged gymnothecial ascomata with globose prototunicate 8-spored asci, and globose or oblate, reticulate ascospores (Solé et al. 2002). Some species of this genus, such as Auxarthron ostraviense and $A$. umbrinum have been reported as producing onychomycosis in humans (Hubka et al. 2013), and Auxarthron brunneum, $A$. compactum and $A$. zuffianum were also isolated from the lungs of kangaroo rats, $A$. conjugatum from lungs of rodents, and $A$. umbrinum from lung of dogs, bats and rodents (Orr et al. 1963, Kuehn et al. 1964).

Malbranchea-like asexual morphs are also present in other taxa of ascomycetes. The genus Arachnomyces (family Arachnomycetaceae, order Arachnomycetales; Malloch \& Cain 1970, Guarro et al. 1993), characterized by the production of brightly coloured cleistothecial ascomata bearing setae, and by the production of an onychocola-like (Sigler et al. 1994) or a malbranchea-like (Udagawa \& Uchiyama 1999) asexual morph, have been also implicated in animal and human infections. Specifically, Arachnomyces nodosetosus and Arachnomyces kanei have been reported as causing nail and skin infections in humans (Sigler \& Congly 1990, Sigler et al. 1994, Campbell et al. 1997, Contet-Audonneau et al. 1997, Kane et al. 1997, Koenig et al. 1997, Gupta et al. 1998, Erbagci et al. 2002, Gibas et al. 2002, Llovo et al. 2002, O’Donoghue et al. 2003, Gibas et al. 2004, Stuchlík et al. 2011, Järv 2015, Gupta et al. 2016). More recently, Arachnomyces peruvianus has been reported to cause cutaneous infection (Brasch et al. 2017) and Arachnomyces glareosus was isolated from nail and skin samples (Gibas et al. 2004; Sun et al. 2019).

The recently described species Spiromastigoides albida, isolated from human lung in USA (Stchigel et al. 2017), also produces a malbranchea-like asexual morph. This genus (family Spiromastigaceae, Onygenales) produces orange gymnothecial ascomata with contorted to coiled appendages and pitted and lenticular ascospores (Kuehn \& Orr 1962, Uchiyama et al. 1995, Unterainer et al. 2002, Hirooka et al. 2016).

Due to the limited knowledge of Malbranchea and their relatives on human infections, we have studied phenotypically and molecularly a set of malbranchea-like fungal strains from clinical specimens received in a fungal reference centre in the USA. Phylogenetic study and an antifungal susceptibility testing were also carried out.

\section{Materials And Methods}

\section{Fungal strains}


Twenty-two malbranchea-like fungal strains (nineteen from human specimens and three from animals) from different locations in USA were included in this study. The strain number, anatomical source, and geographic origin of the specimens are listed in Table 1. They were provided by the Fungus Testing Laboratory of the University of Texas Health Science Centre at San Antonio (UTHSC; San Antonio, Texas, USA).

\section{Phenotypic study}

For cultural characterization, suspensions of conidia were prepared in a semi-solid medium ( $0.2 \%$ agar; $0.05 \%$ Tween 80) and inoculated onto phytone yeast extract agar (PYE; Becton, Dickinson \& Company, Sparks, MD, USA; Carmichael \& Kraus 1959), potato dextrose agar (PDA; Pronadisa, Madrid, Spain; Hawksworth et al. 1995), oatmeal agar (OA; $30 \mathrm{~g}$ of filtered oat flakes, $15 \mathrm{~g}$ agar-agar, $1 \mathrm{~L}$ tap water; Samson et al. 2010), bromocresol purple-milk solids-glucose agar (BCP-MS-G; $80 \mathrm{~g}$ skim milk powder, $40 \mathrm{~g}$ glucose, $10 \mathrm{~mL}$ of $1.6 \%$ of bromocresol purple in $95 \%$ ethanol, $30 \mathrm{~g}$ agar-agar,1 L tap water; Kane \& Smitka 1978), and test opacity tween medium (TOTM; $10 \mathrm{~g}$ bacteriological peptone, $5 \mathrm{~g} \mathrm{NaCl}, 1 \mathrm{~g} \mathrm{CaCl}_{2}, 5 \mathrm{~mL}$ Tween, $5 \mathrm{~mL}$ Tween 80, $15 \mathrm{~g}$ agar-agar, $1 \mathrm{~L}$ tap water; Slifkin 2000). Colonies were characterized after 14 days at $25^{\circ} \mathrm{C}$ in the dark. Potato dextrose agar (PDA) was used to determine the cardinal temperatures of growth. Colour notations were taken according to Kornerup \& Wanscher (1978). Christensen's urea agar (EMD Millipore SA, Darmstadt, Germany; Christensen 1946) was inoculated and incubated for 4 days at $25^{\circ} \mathrm{C}$ in the dark to detect the production of urease. Cycloheximide tolerance was tested growing the fungal strains on Sabouraud dextrose agar (SDA; Pronadisa S.A., Spain) supplemented with $0.2 \%$ cycloheximide (Sigma, USA) at $30{ }^{\circ} \mathrm{C}$ for two weeks. Fungal tolerance to $\mathrm{NaCl}$ was evaluated on SDA adding 3,10 and $20 \% \mathrm{w} / \mathrm{w} \mathrm{NaCl}$, with the same incubation conditions as previously described. The microscopic structures were characterized and measured from wet mountings of slide cultures, using water and $60 \%$ lactic acid. Photo micrographs were taken using a Zeiss Axio-Imager M1 light microscope (Oberkochen, Germany) with a DeltaPix Infinity $X$ digital camera using Nomarski differential interference contrast. The descriptions of the taxonomical novelties were submitted to MycoBank (https://www.mycobank.org/; Crous et al. 2004).

\section{DNA extraction, amplification and sequencing}

Total DNA was extracted as previously described (Valenzuela-Lopez et al. 2018), and the following phylogenetic markers were amplified: the internal transcribed spacers (ITS) (ITS5/ITS4 primers; White et al. 1990, and a fragment of the large subunit (LSU) gene (LROR/LR5 primers; Vilgalys \& Hester 1990; Rehner \& Samuels 1994) of the nrDNA. Amplicons were sequenced at Macrogen Europe (Macrogen Inc., Madrid, Spain) using the same pair of primers. Consensus sequences were obtained by SeqMan software v. 7 (DNAStar Lasergene, Madison, WI, USA). Sequences generated in this work were deposited in GenBank (Table 1).

\section{Phylogenetic analysis}

A preliminary molecular identification of the isolates was carried out with ITS and LSU nucleotide sequences using BLAST (https://blast.ncbi.nlm.nih.gov/Blast.cgi), and only the sequences of ex-type or reference strains from GenBank were included for identification. A maximum level of identity (MLI) $\geq 98 \%$ was used for species-level and < 98\% for genus-level identification. A maximum-likelihood $(\mathrm{ML})$ and Bayesian-inference $(\mathrm{BI})$ phylogenetic analyses of the concatenated ITS-LSU sequences were performed in order to determine the phylogenetic placement of our clinical strains. Species of the order Arachnomycetales were used as outgroup. The sequence alignments and ML / $\mathrm{BI}$ analyses were performed according to Valenzuela-Lopez et al. (2018). The final matrices used for the phylogenetic analysis were deposited in TreeBASE (www.treebase.org; accession number: 25068). 
In vitro antifungal susceptibility testing was carried out following the broth microdilution method from the Clinical and Laboratory Standards Institute (CLSI) protocol M38 (CLSI, 2017) with some modifications. The antifungal drugs tested were amphotericin B (AMB), fluconazole (FLC), voriconazole (VRC), itraconazole (ITC), posaconazole (PSC), anidulafungin (AFG), caspofungin (CFG), micafungin (MFG), terbinafine (TRB), and 5-fluorocytosine (5-FC). Briefly, incubation media, temperature and time were set to the sporulation requirements of every strain, and conidia suspensions were inoculated into the microdilution trays after being adjusted by haemocytometer counts. Incubation was set at $35^{\circ} \mathrm{C}$ (without light or agitation) until the drug-free well displayed a visible fungal growth (minimum 48 h; maximum 10 days) for quantification of the Minimal Effective Concentrations (MEC) for the echinocandins and the Minimal Inhibitory Concentrations (MIC) for the other tested antifungals. The MEC value was stablished as the lowest drug concentration at which short, stubby and highly branched hyphae were observed, while the MIC value was defined as the lowest concentration that completely inhibited the fungal growth. Candida parapsilosis ATCC 22019 was used as the quality control strain in all experiments.

\section{Results}

\section{Fungal diversity}

Table 1 shows the identity of the twenty-two fungal strains studied. The highest number of strains corresponded to Auxarthron umbrinum (4), followed by Auxarthron alboluteum (2), Auxarthron conjugatum (2), and Malbranchea aurantiaca (2). Auxarthron zuffianum, Currahmyces indicus and Malbrancea flocciformis were represented by one strain each. Eight strains were only identified at genus-level (three belonging to Malbranchea, two to Spiromastigoides, two to Arachnomyces, and one to Arthropsis), one strain (FMR 17684) only at family-level (Onygenaceae).

\section{Molecular phylogeny}

Our phylogenetic study included 92 sequences corresponding to 75 species with a total of 1,213 characters (700 ITS and 513 LSU) including gaps, of which 579 were parsimony informative (402 ITS and 177 LSU). The ML analysis was congruent with that obtained in the BI analysis, both displaying trees with similar topologies. The datasets did not show conflict with the tree topologies for the $70 \%$ reciprocal bootstrap trees, which allowed the two genes to be combined for the multi-locus analysis.

Twenty of our strains were placed into a main clade corresponding to the members of the Onygenales (100\% BS / 1 PP), while two were placed in the Arachnomycetales (100\% BS / 1 PP) (Fig. 2). The Onygenales clade was divided into eight clades corresponding to the families Onygenaceae (100\% BS / 1 PP), Gymnascaceae (98\% BS / 1 PP), Nannizziopsiaceae (100\% BS / 1 PP), Helicoarthrosporaceae (100\% BS / 1 PP), Arthrodermataceae (100\% BS / 1 PP), Ajellomycetaceae (97\% BS / 1 PP), Ascosphaeraceae (100\% BS / 1 PP), and Spiromastigaceae (92\% BS / 0.99 PP), which included a basal terminal branch for Pseudospiromastix tentaculata. Most of our strains (17/22) were distributed into several subclades of the Onygenaceae: 15/22 into Auxarthron/Malbranchea subclade (100\% BS / 1 PP), one into a terminal branch (FMR 17683) together Currahmyces indicus (100\% BS / 1 PP), and another one (FMR 17684) into a distant, independent terminal branch. One strain (FMR 17692) was placed into the Gymnascaceae, in a terminal branch together with Arthropsis cirrhata (100\% BS / 1 PP). The Spiromastigaceae included the last two strains (FMR 17686 and FMR 17696), placed into a terminal branch together Malbranchea gypsea (100\% BS / 1 PP). 


\section{Taxonomy}

Since the strains FMR 17685 and FMR 17691 represented two species of Arachnomyces that were different from the other species of the genus, they are proposed as new, i.e. Arachnomyces bostrychodes and Arachnomyces graciliformis, respectively.

Arachnomyces bostrychodes Rodr.-Andr., Cano \& Stchigel, sp. nov. Fig. 3. MycoBank MB 834921.

Etymology: From Greek Bootpuxos-, curl, due to the appearance of the reproductive hyphae.Diagnosis: The phylogenetically closest species to Arachnomyces bostrychodes is A. peruvianum (Fig. 2). Nevertheless, Arachnomyces botrychodes lacks of a sexual morph and racket hyphae (both present in $A$. peruvianum), and produces longer conidia than $A$. peruvianum (4.0-8.0 × 1.0-2.0 $\mu \mathrm{m}$ vs. 4.0-5.0 × 1.0-3.0 $\mu \mathrm{m})$; also, $A$. bostrychodes grows more slowly on OA (13-14 mm diam. after 14 days at $\left.25^{\circ} \mathrm{C}\right)$ than $A$. peruvianum $(30 \mathrm{~mm}$ diam.) (Cain 1957, Brasch et al. 2016). Arachnomyces bostrychodes resembles morphologically Arachnomyces gracilis, but the former grows faster, and produces more twisted branches and lacks sexual morph. Type: United States of America: Texas, from a human's scalp, 2008, N. Wiederhold (CBS H-24452 - holotype; CBS $146926=$ FMR 17685 = UTHSCSA DI18-91 - ex-type cultures; LSU sequences GenBank LR701766).Description: Vegetative hyphae hyaline, septate, branched, smooth- and thin-walled, 1.0-2.0 $\mu \mathrm{m}$ wide. Fertile hyphae well-differentiated, arising as lateral branches from the vegetative hyphae, successively branching to form dense clusters, arcuate, sinuous, contorted or tightly curled, 1.0-2.0 $\mu \mathrm{m}$ wide, forming randomly intercalary and terminally arthroconidia. Conidia enteroarthric, hyaline, one-celled, smooth-walled, cylindrical, barrel-shaped, and finger-like-shaped when terminal, 4.0-8.0 × 1.0-2.0 $\mu \mathrm{m}$, mostly curved and truncated at one or (mostly) both ends, separated from the fertile hyphae by rhexolysis. Chlamydospores, racquet hyphae, setae, and sexual morph not observed.

Culture characteristics: Colonies on PYE reaching 19-20 mm diam. after 2 weeks at $25^{\circ} \mathrm{C}$, elevated, cottony, margins regular, white (5A1), sporulation absent; reverse light orange (5A4). Colonies on PDA reaching 11-12 mm diam. after 2 weeks at $25^{\circ} \mathrm{C}$, elevated, velvety with floccose patches, margins regular, yellowish white (4A2), sporulation abundant; reverse greyish yellow (4B6). Colonies on PDA reaching 13-14 mm diam. after 2 weeks at 30 ${ }^{\circ} \mathrm{C}$, slightly elevated, velvety to floccose, regular margins, white (4A1), sporulation sparse; reverse, greyish yellow (4B6). Colonies on $\mathrm{OA}$ researching 13-14 mm diam. after 2 weeks at $25^{\circ} \mathrm{C}$, flattened, smooth and granulose, irregular margins, yellowish white (2A2) at centre and light yellow (2A5) at edge, sporulation abundant. Exudate and diffusible pigment absent.

Minimum, optimal and maximum temperature of growth (on PDA): $10^{\circ} \mathrm{C}, 30^{\circ} \mathrm{C}$, and $37^{\circ} \mathrm{C}$, respectively. Nonhaemolytic. Casein not hydrolysed. Not inhibited by cycloheximide. Urease and esterase (TOTM) tests positive. Growth occurs at $\mathrm{NaCl} 10 \% \mathrm{w} / \mathrm{w}$, but not at $20 \% \mathrm{w} / \mathrm{w}$.

Arachnomyces graciliformis Rodr.-Andr., Stchigel \& Cano, sp. nov. Fig. 4. MycoBank MB 834923.

Etymology: Because the morphological similarity with Arachnomyces gracilis.Diagnosis: Arachnomyces graciliformis is phylogenetically close to $A$. glareosus and to $A$. minimus (Fig. 2). These three species form common clade together with $A$. nodosetosus and A. jinanicus (84 BS / 1 PP). Unlike A. glareosus and A. minimus, $A$. graciliformis does not produces racquet hyphae nor sexual morph (Gibas et al. 2004) but produces longer conidia

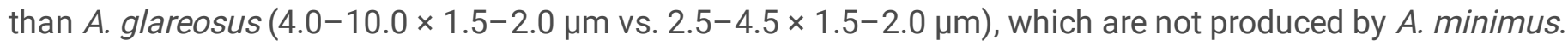
Arachnomyces graciliformis resembles morphologically Arachnomyces gracilis, but the former grows more slowly, produces more twisted fertile branches and does not form a sexual morph (Udagawa \& Uchiyama 1999). Type: 
United States of America: Massachusetts, from an animal's bone, 2012, N. Wiederhold (CBS H-24453 - holotype; CBS 146927 = FMR 17691 = UTHSCSA DI18-97 - ex-type cultures; LSU sequence GenBank LR743668).Description: Vegetative hyphae hyaline, septate, branched, smooth- and thin-walled, 1.0-2.0 $\mu \mathrm{m}$ wide. Fertile hyphae welldifferentiated, arising as lateral branches from the vegetative hyphae, branching repeatedly, sinuous to arcuate or apically coiled, 1.5-2.0 $\mu \mathrm{m}$ wide, forming randomly intercalary and terminally arthroconidia. Conidia enteroarthric, hyaline, unicellular, smooth- and thin-walled, cylindrical or finger-like-shaped when terminal, 4.0-10.0 × 1.5-2.0 $\mu \mathrm{m}$, mostly curved, detached from the fertile hyphae by rhexolysis. Chlamydospores, racquet hyphae, setae, and sexual morph not observed.

Culture characteristics: Colonies on PYE reaching $12-13 \mathrm{~mm}$ diam. after 2 weeks at $25^{\circ} \mathrm{C}$, elevated, velvety to floccose, margins regular, slightly furrowed, yellowish white (3A2), sporulation absent; reverse greyish orange (5B3). Colonies on PDA reaching 9-10 mm diam. after 2 weeks at $25^{\circ} \mathrm{C}$, slightly elevated, velvety to floccose, margins regular, slightly furrowed, yellowish white (1A2), sporulation absent; reverse greyish yellow (4B3). Colonies on PDA reaching 3-4 mm diam. after 2 weeks at $30^{\circ} \mathrm{C}$, slightly elevated, velvety to floccose, margins regular, slightly furrowed, yellowish white (1A2), sporulation absent; reverse, greyish yellow (4B3). Colonies on OA researching 6-7 $\mathrm{mm}$ diam. after 2 weeks at $25^{\circ} \mathrm{C}$, flattened, velvety and granulose, margins irregular, pale yellow (4A3), sporulation absent (conidia appear after 5-6 weeks incubation). Exudate and diffusible pigment absent. Minimum, optimal and maximum temperature of growth (on PDA): $10{ }^{\circ} \mathrm{C}, 25^{\circ} \mathrm{C}$, and $30^{\circ} \mathrm{C}$, respectively. Non-haemolytic. Casein not hydrolysed. Not inhibited by cycloheximide. Urease and esterase tests positive. Growth occurs at $\mathrm{NaCl} 10 \% \mathrm{w} / \mathrm{w}$, but not at $20 \% \mathrm{w} / \mathrm{w}$.

Dichotomous key to Arachnomyces (adapted from Sun et al. 2019).

1a. Homothallic; asexual morph present or not 2

1b. Heterothallic; asexual morph present 6

2a. Peridial setae coiled or circinate; asexual morph absent. 3

2b. Peridial setae straight, tapering towards the apex; asexual morph arthroconidia A. gracilis

3a. Peridial setae slightly nodose; ascospores mostly $<3.5 \mu$ m diameter. 4

3b. Peridial setae smooth-walled; ascospores mostly $>3.5 \mu$ m diamater. 5

4a. Ascospores smooth-walled A. minimus

4b. Ascospores echinulate

A. peruvianus

5a. Ascomata 100-300 um diameter. A. nitidus

5b. Ascomata 500-700 $\mu \mathrm{m}$ diam A. sulphureus

6a. Arthroconidia alternate. 7

6b. Arthroconidia in persistent chains 12

7a. Arthroconidia cylindrical or barrel-shaped; sclerotia present. 8 
8a. Colonies becoming greyish brown, not growing at $35^{\circ} \mathrm{C}$

A. glareosus

8b. Colonies white to pale brown, growing at $35^{\circ} \mathrm{C}$.

A. scleroticus

9a. Arthroconidia subglobose to pyriform. 10

9b. Arthroconidia cylindrical to finger-like-shaped.

10a. Arthroconidia smooth-walled to finely asperulate; setae (produced on the vegetative mycelium) smooth-walled to slightly nodose A. kanei

10b. Mature arthroconidia coarsely verrucose; setae (produced on the vegetative mycelium) strongly nodose. A. pilosus

11a. Fertile hyphae successively branching to form dense clusters, arcuate, sinuous, contorted or tightly curled A. bostrychodes

11b. Fertile hyphae branching but not in clusters; branches only apically coiled A. graciliformis

12a. Setae (produced on the vegetative mycelium) strongly nodose, circinate or loosely coiled at the apex A. nodosetosus

12b. Setae (produced on the vegetative mycelium) strongly nodose, tip straight. A. jinanicus

Since the strain FMR 17692 was placed in the same terminal clade than Arthropsis cirrhata, while the type species of the genus (Arthropsis truncata) is phylogenetically far away (into the order Sordariales; Giraldo et al. 2013), we propose the erection of the new genus Pseudoarthropsis for A. cirrhata, and the new species Pseudarthropsis crassispora.

Pseudoarthropsis Stchigel, Rodr.-Andr. \& Cano, gen. nov. MycoBank MB 834925.

Etymology: From Greek $\psi \varepsilon u \delta \eta ் \varsigma$-, resembling, because the morphological semblance to Arthropsis.

Diagnosis: Mycelium composed by hyaline to orange, septate hyphae. Conidiophores consisting in fertile lateral branches and a part of the main hyphae, which disarticulate in yellowish orange, thin-walled, cylindrical to cuboid enteroarthric conidia, or in hyaline, thick-walled, ellipsoidal, globose to barrel-shaped holoarthric conidia.

Type species: Pseudoarthropsis cirrhata (Oorschot \& de Hoog) Stchigel, Rodr.-Andr. \& Cano.

Pseudoarthropsis cirrhata (Oorschot \& de Hoog) Stchigel, Rodr.-Andr. \& Cano, comb. nov. MycoBank MB 834928.

Basionym: Arthropsis cirrhata Oorschot \& de Hoog, Mycotaxon 20: 130 (1984).

Description: Vegetative hyphae septate, pale yellowish orange, smooth- and thin-walled, dichotomously branched, 2-3 $\mu \mathrm{m}$ wide. Fertile hyphae well differentiated, arising at right angles as recurved lateral branches of the vegetative hyphae, forming septa basipetally to produce chains of enteroarthric conidia. Arthroconidia yellowish orange, 
smooth- and thin-walled, cylindrical to cuboid, often broader than long, 2.5-4.0 $\times 2-3 \mu \mathrm{m}$, truncated at both ends, separated by trapezoid connectives, secession rhexolytic. Colonies on PYE reaching 4-5 mm diam. after 10 days at $25^{\circ} \mathrm{C}$, powdery, fealty, slightly raised, orange (5A7), pale orange (5A5) at centre; reverse brownish orange (7C8), diffusible pigment brown.

Type: CBS 628.83, 1984, from a wall near Schiphol, The Netherlands, collector C.A.N. van Oorschot.

Pseudoathropsis crassispora Rodr.-Andr., Stchigel \& Cano, sp. nov. Fig. 5. MycoBank MB 834930.

Etymology. From Latin crassus-, thick, and -sporarum, spore, because of the thick wall of the conidia.Diagnosis: Pseudoarthropsis crassispora is phylogenetically close to P. cirrhata. Nevertheless, the former produces holoarthric conidia, while they are enteroarthric in the latter. Also, the conidia of $P$. crassispora are ellipsoidal, globose or broadly barrel-shaped, while these are cylindrical to cuboid (often wider than they are long) in P. cirrhata (van Oorschot \& de Hoog 1984). Moreover, the conidia are bigger in P. crassispora than in P. cirrhata (4.5-5.5 $\times 2.5-3.5$ $\mu \mathrm{m}$ vs. $2.5-4.0 \times 2.0-3.0 \mu \mathrm{m}$ ). Also, P. crassispora grows faster than P. cirrhata (on PYE at $25^{\circ} \mathrm{C}$ ), and the maximum temperature of growth is at $37{ }^{\circ} \mathrm{C}$ and $30^{\circ} \mathrm{C}$, respectively. Type: United States of America: Minnesota, from a human's bronchial washing, 2012, N. Wiederhold (CBS H-24454 - holotype; CBS $146928=$ FMR $17692=$ UTHSCSA DI18-98 - ex-type cultures; LSU sequence GenBank LR701763).Description: Vegetative hyphae septate, hyaline, smooth- and thin-walled, mostly straight, occasionally branched, 1.5-2.0 $\mu \mathrm{m}$ wide. Fertile hyphae welldifferentiated, arising as lateral branches of the vegetative hyphae, hyaline, septate, smooth- and thin-walled, erect,

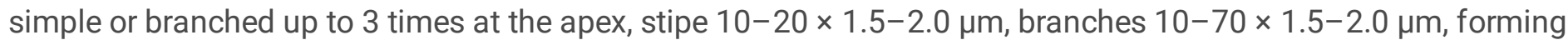
septa basipetally to produce chains of arthroconidia. Conidia holoarthric, unicellular, hyaline, smooth- and thickwalled, ellipsoidal, globose or barrel-shaped, transiently presents as bi-cellular conidia, 2.5-3.5 × 4.5-5.5 $\mu \mathrm{m}$, in chains of up to 20 , separate from the fertile hyphae by schizolysis, rarely by rhexolysis. Chlamydospores, racquet hyphae, setae, and sexual morph not observed.

Culture characteristics: Colonies on PYE reaching 13-14 mm diam. after 2 weeks at $25^{\circ} \mathrm{C}$, slightly elevated, velvety, margins regular, furrowed, yellowish white (3A2) and yellowish grey (4B2) at centre, sporulation abundant; reverse pale yellow (4A3. Colonies on PDA reaching 14-15 mm diam. after 2 weeks at $25^{\circ} \mathrm{C}$, flattened, velvety, margins regular, greenish white (30A2) and pastel green (30A4) at centre, sporulation abundant; reverse pastel yellow (3A4). Colonies on PDA reaching 15-16 mm diam. after 2 weeks at $30^{\circ} \mathrm{C}$, slightly elevated, velvety, margins regular, furrowed, yellowish white (3A2), sporulation sparse; reverse yellow (3A6), with a scarce production of yellowish diffusible pigment. Colonies on OA researching $10-11 \mathrm{~mm}$ diam. after 2 weeks at $25^{\circ} \mathrm{C}$, flattened, velvety to floccose, margins irregular, greenish white (30A2) and pale green (28A3) at centre, sporulation abundant. Exudate and diffusible pigment absent, except on PDA. Minimum, optimal and maximum temperature of growth on PDA: 10 ${ }^{\circ} \mathrm{C}, 30{ }^{\circ} \mathrm{C}$, and $37^{\circ} \mathrm{C}$, respectively. Non-haemolytic. Casein hydrolyzed without $\mathrm{pH}$ change. Not inhibited by cycloheximide. Urease and esterase tests positive. The fungus grows up to $\mathrm{NaCl} 10 \% \mathrm{w} / \mathrm{w}$, but not at $20 \% \mathrm{w} / \mathrm{w}$.

Due to the strain FMR 17683 being placed into a terminal branch of the Onygenaceae together with Currahmyces indicus (Sharma \& Shouche 2019), and because they differ molecularly and phenotypically, we propose the erection of the new species Currahmyces sparsispora.

Currahmyces sparsispora Rodr.-Andr., Cano \& Stchigel, sp. nov. Fig. 6. MycoBank MB 835692.

Etymology: From Latin sparsa-, splashed, -sporarum, spore, due to the disposition of the conidia along the hyphae. 
Diagnosis: Currahmyces sparsispora is phylogenetically close to Currahmyces indicus, however, they can be differentiated because the former has broader hyphae (1.5-2.0 $\mu \mathrm{m}$ vs. 0.7-1.1 $\mu \mathrm{m})$ and lacks a sexual morph (typical gymnothecial ascomata are produced on hair-baited soil plates by $C$. indicus).

Type: United States of America: Florida, from human sputum, 2007, N. Wiederhold (CBS H-24455 - holotype; CBS 146929 = FMR 17683 = UTHSCSA DI18-89 - ex-type cultures; LSU sequence GenBank LR723273).

Description: Vegetative hyphae septate, hyaline, smooth- and thin-walled, mostly straight, rarely branched, 1.5-2.0 $\mu \mathrm{m}$ wide. Fertile hyphae undifferentiated from the vegetative hyphae. Conidia enteroarthric, hyaline, unicellular, smooth- and thin-walled, disposed relatively far from each other along the fertile hyphae, separated by 1-2 evanescent connective cells, cylindrical to slightly barrel-shaped, 3.0-12.0 × 1.0-2.0 $\mu \mathrm{m}$, separated by rhexolysis. Chlamydospores, racquet hyphae, setae, and sexual morph not observed.

Culture characteristics: Colonies on PYE reaching $27-28 \mathrm{~mm}$ diam. after 2 weeks at $25^{\circ} \mathrm{C}$, slightly elevated, velvety to floccose, margins regular, pale orange (5A3) at centre and white (5A1) at edge, sporulation sparse; reverse orange (5A6). Colonies on PDA reaching 23-24 mm diam. after 2 weeks at $25^{\circ} \mathrm{C}$, slightly elevated, velvety, margins regular, light orange (5A5) at centre and orange white (5A2) at edge, sporulation sparse; reverse deep orange (6A8). Colonies on PDA reaching 30-31 mm diam. after 2 weeks at $30^{\circ} \mathrm{C}$, slightly elevated, velvety, slightly furrowed, margins regular, orange (5A6), sporulation sparse; reverse brownish orange (6C8). Colonies on OA reaching 20-21 $\mathrm{mm}$ diam. after 2 weeks at $25^{\circ} \mathrm{C}$, slightly elevated, velvety, margins regular, orange white (5A2) at centre and white (5A1) at edge, sporulation sparse. Exudate and diffusible pigment absent in all culture media tested. Minimum, optimal and maximum temperature of growth on PDA: $10^{\circ} \mathrm{C}, 30^{\circ} \mathrm{C}$, and $37^{\circ} \mathrm{C}$, respectively. Haemolytic. Casein not hydrolysed. Not inhibited by cycloheximide. Urease and esterase tests positive. Growth occurs at $\mathrm{NaCl} 3 \% \mathrm{w} / \mathrm{w}$ and $10 \% \mathrm{w} / \mathrm{w}$, but not at $20 \% \mathrm{w} / \mathrm{w}$.

Taking into account that Auxarthron and Malbranchea are congeneric, as has been in previous studies (Sigler et al. 2002, Sarroco et al. 2015) and here (Fig. 2), and that Malbranchea (Saccardo 1882) has historical priority (International Code of Nomenclature for algae, fungi, and plants; Turland et al. 2018) on Auxarthron (Orr, Kuehn and Plunkett 1963), we transfer the species of Auxarthron (Orr et al. 1963) to Malbranchea as follows:

Malbranchea californiensis (G.F. Orr \& Kuehn) Rodr.-Andr., Stchigel \& Cano, comb. nov.

MycoBank MB 835229.

Basionym: Auxarthron californiense G.F. Orr \& Kuehn, Can. J. Bot. 41: 1442 (1963).

Synonym: Gymnoascus californiensis (G.F. Orr \& Kuehn) Apinis, Mycol. Pap. 96: 12 (1964).

Malbranchea chlamydospora (M. Solé, Cano \& Guarro) Rodr.-Andr., Cano \& Stchigel, comb. nov. MycoBank MB 835230 .

Basionym: Auxarthron chlamydosporum M. Solé, Cano \& Guarro, Stud. Mycol. 47: 108 (2002).

Malbranchea compacta (G.F. Orr \& Plunkett) Rodr.-Andr., Cano \& Stchigel, comb. nov.

MycoBank MB 835231.

Basionym: Auxarthron compactum G.F. Orr \& Plunkett, Can. J. Bot. 41: 1453 (1963). 
Malbranchea concentrica (M. Solé, Cano \& Guarro) Rodr.-Andr., Stchigel \& Cano, comb. nov. MycoBank MB 835232.

Basionym: Auxarthron concentricum M. Solé, Cano \& Guarro, Stud. Mycol. 47: 106 (2002).

Malbranchea conjugata (Kuehn) Rodr.-Andr., Cano \& Stchigel, comb. nov. MycoBank MB 835233.

Basionym: Myxotrichum conjugatum Kuehn, Mycologia 47: 883 (1956) [1955].

Synonym: Auxarthron conjugatum (Kuehn) G.F. Orr \& Kuehn, Mycotaxon 24: 148 (1985).

Malbranchea longispora (Stchigel, Y. Marín, Guarro \& Cano) Rodr.-Andr., Stchigel \& Cano, comb. nov. MycoBank MB 835235.

Basionym: Auxarthron longisporum Stchigel, Y. Marín, Guarro \& Cano, Persoonia 31: 267 (2013).

Malbranchea ostraviensis (Hubka, Dobiášová \& M. Kolařík) Rodr.-Andr., Cano \& Stchigel, comb. nov. MycoBank MB 835236.

Basionym: Auxarthron ostraviense Hubka, Dobiášová \& M. Kolařík, Med. Mycol. 50: 619 (2012).

Malbranchea pseudauxarthron (G.F. Orr \& Kuehn) Rodr.-Andr., Stchigel \& Cano, comb. nov. MycoBank MB835237.

Basionym: Auxarthron pseudauxarthron G.F. Orr \& Kuehn, Mycologia 64: 67 (1972).

Malbranchea umbrina (Boud.) Rodr.-Andr., Cano \& Stchigel, comb. nov. MycoBank MB 835238.

Basionym: Gymnoascus umbrinus Boud., Bull. Soc. mycol. Fr. 8: 43 (1892).

Synonym: Auxarthron brunneum (Rostr.) G.F. Orr \& Kuehn, Can. J. Bot.41: 1446 (1963).

Auxarthron umbrinum (Boud.) G.F. Orr \& Plunkett, Can. J. Bot. 41: 1449 (1963).

Auxarthron thaxteri (Kuehn) G.F. Orr \& Kuehn, Mycologia 63: 200 (1971).

Gymnoascus subumbrinus A.L. Sm. \& Ramsb., Trans. Br. Mycol. Soc. 5: 424 (1917) [1916].

Gymnoascus umbrinus var. thaxteri (Kuehn) Apinis, Mycol. Pap. $96: 14$ (1964).

Myxotrichum brunneum Rostr., Bot. Tidsskr. 19: 216 (1895).

Myxotrichum thaxteri Kuehn, Mycologia 47: 878 (1956) [1955].

Malbranchea zuffiana (Morini) Rodr.-Andr., Stchigel \& Cano, comb. nov. MycoBank MB 835239.

Basionym: Gymnoascus zuffianus Morini, Mem. R. Accad. Sci. Ist. Bologna, Ser. 4 10: 205 (1889).

Synonym: Auxarthron zuffianum (Morini) G.F. Orr \& Kuehn, Can. J. Bot. 41: 1445 (1963).

We also revalidate the Malbranchea species listed below:

Malbranchea albolutea Sigler \& J.W. Carmich., Mycotaxon 4(2): 416 (1976). 
Synonym: Auxarthron alboluteum Sigler, Hambl. \& Flis, Stud. Mycol. 47: 118 (2002).

Malbranchea filamentosa Sigler \& J.W. Carmich., Mycotaxon 15: 468 (1982).

Synonym: Auxarthron filamentosum Sigler, Hambl. \& Flis, Stud. Mycol. 47: 116 (2002).

Because in a Blast search using the ITS and LSU nucleotide sequences from the ex-type strains, Malbranchea circinata and Malbranchea flavorosea match with taxa into the family Myxotrichaceae, both species are excluded to the genus.

After examination of the lectotype of Auxarthron indicum (Patil \& Pawar 1987), we concluded that this fungus must be excluded from Malbranchea because its sexual morph differs mainly from all species described for the former genus. Whereas Auxarthron indicum produces smooth-walled ellipsoidal ascospores and gymnothecial ascomata lacking of true appendages, in Malbranchea spp. the ascospores are globose and mostly ornamented, and the ascomata have appendages. Based on the fact that there is no type strain of this species, we consider it as invalid.

Consequently, an emended description of the genus Malbranchea is provided as follows:

Malbranchea Sacc. MycoBank MB 8833.

Vegetative hyphae septate, hyaline, smooth- and thin-walled, straight or branched. Asexual morph consisting in undifferentiated fertile hyphae, and/or well-differentiated lateral branches, curved or not, which form randomly or basipetally terminal and intercalary arthroconidia. Conidia enteroarthric, rarely holoarthric, unicellular, hyaline, smooth- and thin-walled, mostly cylindrical, barrel-shaped, or irregularly shaped, sometimes cylindrical, detached from the fertile hyphae by rhexolysis. Sexual morph (when present) consisting in ascomata formed by of an anastomosing network of orange to brown, ornamented or not thick-walled hyphae (gymnothecia), bearing elongate appendages and/or spine projections, within there are small, evanescent, inflated asci which forms eight globose to oblate ascospores, whose cell wall is ornamented with a (coarse or thin) reticulate pattern. Species homothallic or heterothallic, thermotolerant or thermophilic, keratinolytic, chitinolytic or cellulolytic.

Despite the strain FMR 17681 being placed phylogenetically close to Malbranchea ostraviense and Malbranchea umbrina, it differs genetically and phenotypically from both species, therefore we propose the new species Malbranchea gymnoascoidea as follows:

Malbranchea gymnoascoides Rodr.-Andr., Stchigel \& Cano, sp. nov. Fig. 7. MycoBank

MB 835212.

Etymology. Because to the ascomata are morphologically like to those of Gymnoascus reessii.Diagnosis: Malbranchea gymnoascoides is phylogenetically close to M. ostraviensis and M. umbrina (Fig. 2). Nevertheless, $M$. gymnoascoides produces smaller ascomata (up to $250 \mu \mathrm{m}$ diam. in M. gymnoascoides vs. up to 450 and up to 600 $\mu \mathrm{m}$ diam. in both, M. ostraviensis and M. umbrina, respectively) (Orr et al. 1963, Hubka et al. 2013). Also, the peridial appendages of $M$. gymnoascoides are longer than those of $M$. umbrina $(250-400 \mu \mathrm{m}$ vs. 5-72 $\mu \mathrm{m})$, but shorter than those of $M$. ostraviensis (of 350-600 $\mu \mathrm{m}$ long). The ascospores of $M$. gymnoascoides are like to those of $M$. ostraviensis (smooth-walled under the bright field microscope, oblate to globose, 2.5-3.5 $\mu \mathrm{m}$ diam), whereas those of $M$. umbrina are lenticular and measure 2.8-4.0 × 2.1-2.6 $\mu \mathrm{m}$. Moreover, the arthroconidia of $M$. gymnoascoides are larger than those of M. umbrina (6.0-10.0 × 1.5-2.0 $\mu \mathrm{m}$ and 2.6-7.0 × $1.4 \mu \mathrm{m}$, respectively). 
Malbranchea ostraviensis also produces a pinkish to red diffusible pigment on MEA, PDA and SDA, a feature not observed in M. gymnoascoides nor in M. umbrina. Both Malbranchea gymnoascoides as well as of M. umbrina can grow slowly at $35^{\circ} \mathrm{C}$, whereas the maximum temperature of growth for M. ostraviensis is of $32^{\circ} \mathrm{C}$. Type: United State of America: Texas, from human's bronchial washing, 2005, N. Wiederhold (CBS H-24456 - holotype; CBS 146930 = FMR 17681 = UTHSCSA DI18-87 - ex-type cultures; LSU sequence GenBank LR701758).

Description: Vegetative hyphae septate, hyaline, smooth- and thin-walled, mostly straight, rarely branched, 1.5-2.5 $\mu \mathrm{m}$ wide. Asexual morph consisting in undifferentiated fertile hyphae which form randomly intercalary and terminally arthroconidia. Conidia enteroarthric, unicellular, hyaline, smooth- and thin-walled, mostly barrel-shaped, sometimes cylindrical or irregularly-shaped, 6.0-10.0 × 1.5-2.0 $\mu \mathrm{m}$, detached by rhexolysis. Ascomata gymnothecial, solitary or in clusters, hyaline at first, becoming orange brown with the age, globose or nearly so, 130-250 $\mu \mathrm{m}$ diam. excluding the appendages, which cover entirely the surface. Peridial hyphae septate, orange brown, branching and anastomosing to form a reticulate network, asperulate, very thick-walled, 3.5-5.5 $\mu \mathrm{m}$ wide, fragmenting by the septa when ageing, with lateral appendages. Appendages 0-1-septate, orange brown, asperulate, thick-walled, progressively tapering towards the apex, apex sinuous, $250-400 \mu \mathrm{m}$ long, connected by basal knuckle joints. Asci 8-spored, globose or nearly so, 4-7 $\mu$ m diam., soon deliquescent. Ascospores unicellular, hyaline at first, yellowish in mass when mature, smooth-walled under bright field microscope, globose, 2.5-3.5 $\mu \mathrm{m}$ diam.

Culture characteristics: Colonies on PYE reaching $46-47 \mathrm{~mm}$ diam. after 2 weeks at $25^{\circ} \mathrm{C}$, slightly elevated, velvety to floccose, margins regular, pale orange (5A3) at centre and white (5A1) at edge, sporulation sparse; reverse orange (5A6). Colonies on PDA reaching 36-37 mm diam. after 2 weeks at $25^{\circ} \mathrm{C}$, slightly elevated, velvety, margins regular, light orange (5A5) at centre and orange white (5A2) at edge, sporulation sparse; reverse deep orange (6A8). Colonies on PDA reaching 31-32 mm diam. after 2 weeks at $30^{\circ} \mathrm{C}$, slightly elevated, velvety, margins regular, slightly furrowed, orange (5A6), sporulation sparse; reverse brownish orange (6C8). Colonies on OA reaching 21-22 $\mathrm{mm}$ diam. after 2 weeks at $25^{\circ} \mathrm{C}$, slightly elevated, velvety, margins regular, orange white (5A2) at centre and white (5A1) at edge, sporulation sparse. Exudate and diffusible pigment absent in all culture media tested. Minimum, optimal and maximum temperature of growth on PDA: $10^{\circ} \mathrm{C}, 25^{\circ} \mathrm{C}$, and $35^{\circ} \mathrm{C}$, respectively. Non-haemolytic. Casein hydrolysed without pH change. Not inhibited by cycloheximide. Urease and esterase tests positive. Growth occurs at $\mathrm{NaCl} 10 \% \mathrm{w} / \mathrm{w}$, but not at $20 \% \mathrm{w} / \mathrm{w}$.

Despite the strain FMR 17695 being phylogenetically close to Malbranchea longispora, it differs phylogenetically and morphologically from it. Consequently, we propose the erection of the new species Malbranchea multiseptata.

Malbranchea multiseptata Rodr.-Andr., Cano \& Stchigel, sp. nov. Fig. 8. MycoBank MB 835213.

Etymology. From Latin multi-, many, and - septatae, septa, because the vegetative hyphae are multiseptate.Diagnosis: Malbranchea multiseptata is phylogenetically linked to $M$. longispora. Nevertheless, $M$. multiseptata does not form chlamydospores nor a sexual morph as in M. longispora (Crous et al. 2013). Also, M. multiseptata produces shorter conidia (3.0-9.0 × 1.5-2.0 $\mu \mathrm{m})$ than those of M. Iongispora (4.0-24.0 $\times 1.0-5.5$ $\mu \mathrm{m})$. Type: United States of America: Texas, from human's bronchial washing, 2014, N. Wiederhold (CBS H-24457 holotype; CBS 146931 = FMR 17695 = UTHSCSA DI18-101 - ex-type cultures; LSU sequence GenBank LR701760).Description: Vegetative hyphae hyaline, smooth- and thin-walled straight to sinuous, sparsely branched, 1.0-2.0 $\mu \mathrm{m}$ wide, becoming highly septate with the age, septa thickened. Fertile hyphae arising as lateral branches (sometimes arranged opposite each other) from the vegetative hyphae, unbranched, straight or slightly sinuous, 
1.5-2.0 $\mu \mathrm{m}$ wide, forming randomly intercalary and terminally arthroconidia. Conidia enteroarthric, unicellular, hyaline, smooth- and thin-walled, separated by evanescent connective cells, cylindrical, 3.0-9.0 × 1.5-2.0 $\mu \mathrm{m}$, rounded at the end when terminal, rhexolytic secession. Chlamydospores, racquet hyphae, setae, and sexual morph not observed.

Culture characteristics: Colonies on PYE reaching $35-36 \mathrm{~mm}$ diam. after 2 weeks at $25^{\circ} \mathrm{C}$, elevated, velvety to floccose, margins regular, white (5A1), sporulation sparse; reverse greyish yellow (4B4). Colonies on PDA reaching 34-35 mm diam. after 2 weeks at $25^{\circ} \mathrm{C}$, slightly elevated, velvety to floccose, margins regular, white (5A1), sporulation absent; reverse yellowish white (3A2). Colonies on PDA reaching 27-28 mm diam. after 2 weeks at 30 ${ }^{\circ} \mathrm{C}$, slightly elevated, velvety to floccose, margins regular, white (5A1), sporulation absent; reverse pale yellow (3A3). Colonies on OA researching $37-38 \mathrm{~mm}$ diam. after 2 weeks at $25^{\circ} \mathrm{C}$, flattened, barely perceptible growth, not distinguishable colour, sporulation sparse. Exudate and diffusible pigment absent in all culture media tested. Minimum, optimal and maximum temperature of growth on PDA: $10^{\circ} \mathrm{C}, 25^{\circ} \mathrm{C}$, and $35^{\circ} \mathrm{C}$, respectively. Haemolytic. Casein hydrolyzed without $\mathrm{pH}$ change. Not inhibited by cycloheximide. Urease positive. Growth occurs at $\mathrm{NaCl} 3 \%$ w/w, but not at $10 \%$ w/w. Neither grow on TOTM.

Because the strain FMR 17680 was placed phylogenetically close to Malbranchea filamentosa but in a separate terminal branch, and because both differ morphologically and genotypically, the new species Malbranchea stricta is proposed.

Malbranchea stricta Rodr.-Andr., Stchigel \& Cano, sp. nov. Fig. 9. MycoBank MB 835219.

Etymology: Latin stricta, strict, due to the production of the typical reproductive structures of the genus.Diagnosis: Malbranchea stricta is phylogenetically close to M. filamentosa. Also, both species lack of a sexual morph (Sigler et al. 2002). However, M. filamentosa produces more regularly shaped conidia than M. stricta, and forms thick-walled brown setae, structures absent in M. stricta. Type: United States of America: Florida, human nail, 2003, N. Wiederhold (CBS H-24458 - holotype; CBS 146932 = FMR 17680 = UTHSCSA DI18-86 - ex-type cultures; LSU sequence GenBank LR701639).

Description: Vegetative hyphae hyaline, smooth- and thin-walled, straight to sinuous, sparsely branched, 1.5-2.0 $\mu \mathrm{m}$ wide. Fertile hyphae well-developed, arising as lateral branches from the vegetative hyphae, mostly unbranched, right or slightly sinuous, contorted or arcuate at the end, up to $25 \mu \mathrm{m}$ long, 1.5-2.0 $\mu \mathrm{m}$ wide, or developing at the extremes of the vegetative hyphae, in both cases forming arthroconidia randomly intercalary and terminally. Arthroconidia enteroarthric, hyaline, becoming yellowish with the age, barrel-shaped, " $T$ "-shaped, "Y"-shaped, fingershaped or irregularly-shaped 2.0-6.0 × 1.0-2.0 $\mu \mathrm{m}$, with rhexolytic secession. Chlamydospores, racquet hyphae, and sexual morph not observed.

Culture characteristics: Colonies on PYE reaching 32-33 mm diam. after 2 weeks at $25^{\circ} \mathrm{C}$, flattened, velvety, regular margins, furrowed, white (4A1), sporulation sparse; reverse pale orange (5A3). Colonies on PDA reaching 20-21 $\mathrm{mm}$ diam. after 2 weeks at $25^{\circ} \mathrm{C}$, slightly elevated, velvety to floccose, regular margins, white (3A1), sporulation abundant; reverse pale yellow (4A3). Colonies on PDA reaching 20-21 mm diam. after 2 weeks at $30^{\circ} \mathrm{C}$, slightly elevated, velvety to floccose, margins regular, white (3A1), sporulation abundant; reverse yellowish brown (5E8) at centre and greyish yellow (4B5) at the margins. Colonies on OA researching 16-17 mm diam. after 2 weeks at 25 ${ }^{\circ} \mathrm{C}$, flattened, granulose, white (3A1), margins regular, sporulation sparse. Exudate and diffusible pigment absent. Minimum, optimum and maximum temperature of growth on PDA: $10^{\circ} \mathrm{C}, 30^{\circ} \mathrm{C}$, and $37^{\circ} \mathrm{C}$, respectively. Colonies 
haemolytic (on BA), and casein hydrolyzed without pH changes at $25^{\circ} \mathrm{C}$ (on BCP-MS-G). Not inhibited by cycloheximide. Urease and esterase tests positive. Growth occurs at $\mathrm{NaCl} 10 \% \mathrm{w} / \mathrm{w}$, but not at $20 \% \mathrm{w} / \mathrm{w}$.

Dichotomous key to Malbranchea spp. (adapted from Sigler \& Carmichael 1976, Solé et al. 2002, and Hubka et al. 2013).

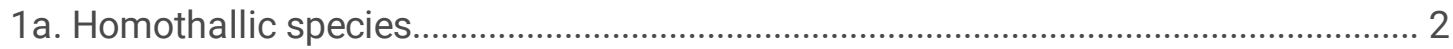

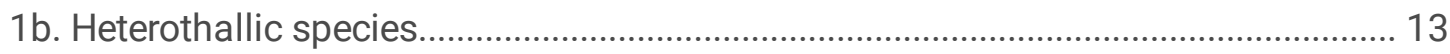

2a. Peridial appendages longer than 150 um long ............................................................. 3

2b. Peridial appendages shorter or absent........................................................... 8

3a. Appendages 350-600 $\mu \mathrm{m}$ in length; diffusible pigment pinkish to reddish; not growing at 35 ${ }^{\circ} \mathrm{C}$. M. ostraviensis

3b. Those features not combined. 4

4a. Ascospores smooth-walled under bright field microscope

M. gymnoascoides

4b. Ascospores reticulate. 5

5a. Peridial cells short, 4-12 $\mu \mathrm{m}$ in length; peridial projections with truncate ends M. compacta

5b. Peridial cells longer; peridial projections with mostly acute ends. 6 6a. Ascospores usually exceeding $4 \mu \mathrm{m}$ diameter. M. californiensis

6b. Ascospores $\leq 4 \mu \mathrm{m}$ diam 7

7a. Species growing at $37^{\circ} \mathrm{C}$ M. conjugata

7b. No growth at $37^{\circ} \mathrm{C}$ M. umbrina

8a. Asexual morph not produced. M. pseudoauxarthron

8b. Malbranchea-like asexual morph present 9

9a. Ascomata with spine-like peridial projections, $27-40 \mu \mathrm{m}$ in length M. zuffiana

9b. Ascomata without peridial projections. 10

10a. Colonies on PDA brown M. kuehnii

10b. Colonies on PDA otherwise 11

11a. Peridial hyphae smooth-walled. M. concentrica

11b. Peridial hyphae strongly ornamented; chlamydospores present. 12 
12a. Arthroconidia $2-10 \times 2.5-3.5 \mu \mathrm{m}$; growing above $30^{\circ} \mathrm{C}$ M. chlamydospora

12b. Arthroconidia 4-24 × 1.0-5.5 $\mu \mathrm{m}$; not growing above $30^{\circ} \mathrm{C}$ M. longispora

13a. Fertile hyphae arcuate or curved 14

13b. Fertile hyphae straight to sinuous, branched or not 21

14a. Fertile hyphae coiled 15

14b. Fertile hyphae curved or arcuate. 16

15a. Thermophilic; conidia 2.5-4.5 $\mu \mathrm{m}$ wide. M. cinnamomea

15b. Not thermophilic; conidia narrower. M. pulchella

16a. Colonies orange 17

16b. Colonies different 18

17a. Aleuroconidia laterally or terminally dispersed. M. chrysosporoidea

17b. Aleuroconidia absent. M. aurantiaca

18a. Colonies golden yellow, exudate brown, diffusible pigment yellow........ M. graminicola

18b. Features are not combined. 19

19a. Sexual morph produced by in vitro mating of compatible strains. M. albolutea

19b. Sexual morph not formed. 20

20a. Thick-walled brown setae produced on OA from the vegetative mycelium M. filamentosa

20b. Setae not produced. M. arcuata

21a. Fertile hyphae unbranched or scarcely branched 22

21b. Fertile hyphae branched. 23

22a. Arthroconidia cylindrical; becoming many septate with the age...... M. multiseptata

22b. Arthroconidia barrel-shaped, " $T$ "-shaped, " $Y$ "-shaped, finger-shaped or more irregular; vegetative hyphae regularly septate. M. stricta

23a. Fertile hyphae branching acutely, displaying a tree-like appearance. M. dendritica

23b. Fertile hyphae branching pattern otherwise 24

24a. Fertile hyphae repeatedly branched, in dense tufts. M. flocciformis 
25a. Colonies buff or tan M. fulva

25b. Colonies lemon yellow. M. flava

Despite the strain FMR 17684 being placed phylogenetically into the Onygenaceae, is paraphyletic and distant from the other members of the family, therefore this fungus is proposed as the type species of the new genus Pseudomalbranchea.

Pseudomalbranchea Rodr.-Andr., Cano \& Stchigel, gen. nov. MycoBank MB 835220.

Etymology: Because the morphological similarity with Malbranchea.

Description: Mycelium sparse, composed of hyaline, smooth- and thin-walled septate hyphae. Asexual morph consisting of mostly enteroarthric -occasionally holoarthric- conidia, intercalary disposed along unbranched vegetative hyphae, solitary or in short chains, with rhexolytic or rarely schizolysic secession. Arthroconidia onecelled, hyaline, smooth- and thick-walled, cylindrical but becoming globose with the age. Chlamydospores, racquet hyphae and sexual morph not observed.

Type species: Pseudomalbranchea gemmata Rodr.-Andr., Cano \& Stchigel. MycoBank MB 835221.

Pseudomalbranchea gemmata Rodr.-Andr., Cano \& Stchigel, sp. nov. Fig. 10. MycoBank MB 835221.

Etymology: From the Latin gemmatum, jewelled, because the swollen conidia disposed in chains.

Diagnosis: Pseudomalbranchea gemmata is phylogenetically close to Uncinocarpus reesii and Amauroascus volatilis-patellis. However, it does not produce a sexual morph and it differs from $U$. reessi and $A$. volatilis-patellis by the production of longer arthroconidia (4.0-11.0 × 2.0-3.5 $\mu \mathrm{m}$ in P. gemmata vs. 3.5-6.0 $2.5-3 \mu \mathrm{m}$ in U. reessi, and 4.0-5.4 × 2.0-3.0 in A. volatilis-patellis; Orr \& Kuehn 1972, Sigler \& Carmichael 1976, Currah 1985). As well as A. volatilis-patellis, P. gemmata lacks appendages, which are present and similar to the asexual morph in $U$. reessi (Currah 1985). Type: United States of America: Florida, from human's bronchial washing, 2014, N. Wiederhold (CBS H-24459 - holotype, CBS 146933 = FMR 17684 = UTHSCSA DI18-90 - ex-type cultures; LSU sequence GenBank LR701762).Description: Mycelium sparse, composed of hyaline, smooth- and thin-walled, sparsely septate hyphae, 1.0-2.0 um wide. Conidia enteroarthric (occasionally holoarthric), intercalary disposed along unbranched vegetative hyphae, one-celled, solitary or in short chains of up to 7, one-celled, hyaline, smooth- and thick-walled, cylindrical but becoming globose with the age, 4.0-11.0 × 2.0-3.5 $\mu \mathrm{m}$, liberated from the fertile hyphae by rhexolysis (rarely by schizolysis). Chlamydospores, racquet hyphae and sexual morph not observed.

Culture characteristics: Colonies on PYE reaching 22-23 mm diam. after 2 weeks at $25^{\circ} \mathrm{C}$, slightly elevated, velvety, margins regular, pale yellow (3A3), sporulation sparse; reverse brown (6E6). Colonies on PDA reaching 24-25 mm diam. after 2 weeks at $25^{\circ} \mathrm{C}$, slightly elevated, velvety, margins regular, pale yellow (3A3), sporulation sparse; reverse light yellow (4A5). Colonies on PDA reaching $25-26 \mathrm{~mm}$ diam. after 2 weeks at $30{ }^{\circ} \mathrm{C}$, flattened, radially folded, velvety, margins regular, pale yellow (3A3), sporulation sparse; reverse light yellow (4A5). Colonies on OA reaching 28-29 mm diam. after 2 weeks at $25^{\circ} \mathrm{C}$, flattened, velvety to granulose, irregular margins, white (6A1), sporulation sparse. Exudate and diffusible pigment lacking. Minimum, optimum and maximum temperature of growth on PDA: $10^{\circ} \mathrm{C}, 30^{\circ} \mathrm{C}$, and $37^{\circ} \mathrm{C}$, respectively. Colonies haemolytic, casein not hydrolyzed. The fungus was 
not inhibited by cycloheximide. Urease and esterase tests positive. Growth occurs at $\mathrm{NaCl} 3 \% \mathrm{w} / \mathrm{w}$, but not higher concentration.

Because the strains FMR 17686 and FMR 17696 were placed together in a terminal branch close related to the extype strain of M. gypsea into the Spiromastigaceae clade (Fig. 2), M. gypsea is renamed as Spiromastigoides gypsea, and the former strains are proposed as belonging to the new species Spiromastigoides geomyces.

Spiromastigoides geomycoides Stchigel, Rodr.-Andr. \& Cano, sp. nov. Fig. 11. MycoBank MB 835222.

Etymology:Because produce conidiophores morphologically similar to those of the genus Geomyces.Diagnosis: Spiromastigoides geomycoides is phylogenetically close to $S$. gypsea. However, $S$. geomycoides produces smaller conidia $(1.5-2.5 \times 1.0-2.0 \mu \mathrm{m})$ than $S$. gypsea [(2.5)3-6(9) $\times 2-2.5 \mu \mathrm{m}]($ Sigler \& Carmichael 1976). Also, $S$. geomycoides grows faster than S. gypsea on PYE at $35^{\circ} \mathrm{C}$. Type: United States of America: Illinois, from a human foot skin, 2014, N. Wiederhold (CBS H-24460 - holotype, CBS 146934 = FMR 17696 = UTHSCSA DI18-102 - ex-type cultures; LSU sequence GenBank LR701768).Description: Mycelium abundant, composed of hyaline, smooth- and thin-walled, septate, branched, 1.0-2.0 $\mu \mathrm{m}$ wide hyphae, septa thickened with age. Fertile hyphae arising as lateral branches, straight or slightly curved, unbranched or, rarely, with a branching pattern similar to that of the conidiophores of Geomyces, septate, hyaline, smooth- and thin-walled, producing intercalary and terminally arthroconidia separated by 1-2 empty intermediary cells. Conidia enteroarthic, unicellular, hyaline, mostly barrelshaped, less frequently " $\mathrm{T}$ "-shaped or cylindrical, 1.5-2.5 × 1.0-2.0 $\mathrm{mm}$, rhexolytic dehiscence. Chlamydospores, racquet hyphae and sexual morph not observed.

Culture characteristics: Colonies on PYE reaching 24-25 mm diam. after 2 weeks at $25^{\circ} \mathrm{C}$, flattened, velvety, furrowed, regular margins, white (4A1), abundant sporulation; reverse, pale orange (5A3). Colonies on PDA reaching 26-27 mm diam. after 2 weeks at $25^{\circ} \mathrm{C}$, flattened, velvety, regular margins, white (4A1), abundant sporulation; reverse, yellowish white (4A2). Colonies on PDA reaching more than $90 \mathrm{~mm}$ diam. after 2 weeks at $30{ }^{\circ} \mathrm{C}$, flattened, velvety, regular margins, yellowish white (4A2), sporulation absent; reverse, pale yellow (4A3). Colonies on OA researching 20-21 mm diam. after 2 weeks at $25^{\circ} \mathrm{C}$, flattened, granulose, regular margins, white (4A1), abundant sporulation. Exudate and diffusible pigment absent in all culture media tested. Minimum, optimum and maximum temperature of growth on PDA: $5{ }^{\circ} \mathrm{C}, 30^{\circ} \mathrm{C}$, and $37^{\circ} \mathrm{C}$, respectively. Colonies non-haemolytic. Casein not hydrolyzed. Resistent to cycloheximide. Urease negative and esterase positive. Growth occurs at $\mathrm{NaCl} 10 \% \mathrm{w} / \mathrm{w}$, but not at $20 \%$ w/w.

Other specimens examined: United States of America: Minnesota, from blood, 2009, N. Wiederhold (FMR 17686).

Spiromastigoides gypsea (Sigler \& Carmichael) Stchigel, Rodr.-Andr. \& Cano, comb. nov. MycoBank MB 835228.

Basionym: Malbranchea gypsea Sigler \& Carmichael, Mycotaxon 4: 455 (1976). MycoBank MB 317129.

Description (adapted from the original work): Arthroconidia produced intercalary or terminally along of straight primary hyphae, or on short or long lateral branches, separated each one by one or more alternate empty cells, or, rarely, formed immediately adjacent to each other. Arthroconidia unicellular, hyaline, smooth- and thin-walled, cylindrical or slightly barrel-shaped, (2.5) 3-6 (9) × 2-2.5 $\mu \mathrm{m}$, slightly broader than the interconnecting cells. No sexual morph obtained by matting. Colonies on PYE reaching 17-39 mm after three weeks at room temperature, chalky white to creamy white, downy to velvety, slightly raised, surface folded to convoluted, umbonated at centre, 
reverse buff. Optimum temperature of growth $25-30^{\circ} \mathrm{C}$. Maximum temperature of growth $37^{\circ} \mathrm{C}$ (but strain depending).

Dichotomous key to Spiromastigoides spp. (adapted from Hirooka et al. 2016).

1a. Homothallic 2

1b. Heterothallic 6

2a. Ascospores globose to subglobose, reticulate S. sphaerospora

2b. Ascospores oblate, equatorial thickening present or not. 3

3a. Ascospores with equatorial thickening 4

3b. Ascospores without such equatorial thickening. 5

4a. Ascomata appendages straight or slightly undulate; ascospores yellow, smooth-walled, pitted under SEM. S. alatospora

4b. Ascomata appendages slightly undulate or wavy; ascospores pale yellowish brown, minutely punctate under SEM S. saturnispora

5a. Ascospores punctate, sometimes with a few fine grooves in the polar region, $2.5-2.9 \times 2.0-2.5$ $\mu \mathrm{m}$. S. warcupii

5b. Ascospores lens-shaped, regularly pitted, $3.0 \times 2.0 \mu \mathrm{m}$ S. sugiyamae

6a. Asexual morph chrysosporium-like; sterile ascomata present. S. asexualis

6b. Asexual morph not so. 7

7a. Asexual morph malbranchea-like. 8

7b. Asexual morph more complex. 11

8a. Fertile hyphae straight, branched.

S. gypsea

8b. Fertile hyphae curved. 9

9a. Fertile hyphae successively branched to form sporodochia-like structures. S. albida

9b. Fertile hyphae unbranched or scarcely branched. 10

10a. Fertile hyphae unbranched or sparsely branched, curved, up to $28 \mu \mathrm{m}$ long; chlamydospores present. S. curvata

10b. Fertile hyphae unbranched, slightly curved, up to $15 \mu \mathrm{m}$ long; chlamydospores absent. S. minimus

11a. Conidiophores unbranched or scarcely branched. S. geomycoides 
12a. Conidiophores up to $300 \mu \mathrm{m}$ in length, verticillate. S. kosraensis

12b. Conidiophores $100-150 \mu \mathrm{m}$ in length, with pyramidal or bush-like branching. 13

13a. Conidiophores up to $150 \mu \mathrm{m}$ long, with pyramidal branching. S. pyramidalis

13b. Conidiophores up to $100 \mu \mathrm{m}$ long, with bush-like branching. S. frutex

\section{In vitro antifungal susceptibility testing}

The results of the antifungal susceptibility test are summarized in Table 2. In general, the echinocandins (AFG, CFG and MFG) displayed the most potent in vitro antifungal activity, but TRB and PSC also demonstrated a good activity against these fungi. In contrast, limited to no inhibition of growth was observed with AMB, FLC, ITC and 5-FC. Antifungal activity was evaluated against all strains with the exception of FMR 17691, due to the scarce production of conidia and because this strain does not grow in RPMI medium, even after two weeks of incubation.

\section{Discussion}

To our knowledge, this is the main study on malbranchea-like fungi from a clinical origin. We have shown that several of these fungi have not been reported previously from human specimens, and although the pathologic role remains uncertain, their diversity is of interest since some represent new species.

Morphological and physiological characterization and phylogenetic analysis has allowed us to identify fifteen strains as belonging to the genus Malbranchea (syn. Auxarthron), of which three of them are proposed as new species. These results indicate a high diversity of onygenalean fungi in these sorts of substrates, which may be difficult to differentiate only by using phenotypic characteristics.

All strains belonging to Malbranchea displayed thermotolerance, suggesting the potential pathogenicity of this genus in animals, including humans, as has been previously noted by others (Saccardo 1908, Saccardo \& Trotter 1913, Cooney \& Emerson 1964, Sigler \& Carmichael 1976). In fact, all them were able to grow at $30^{\circ} \mathrm{C}$, and most of them at $35-37^{\circ} \mathrm{C}$.

Malbranchea-like fungi were most commonly isolated from the respiratory tract (40\%) followed by nails and skin (27.2 \%). Currahmyces sparsispora, Malbranchea albolutea, M. conjugata, M. gymnoascoides, M. multiseptata, Pseudoarthropsis crassispora and Pseudomalbranchea gemmata were all recovered from respiratory tract specimens (mostly obtained by bronchial-alveolar washing), while those of $M$. umbrina were isolated from the widest variety of anatomical sites. The rest of the taxa isolated were mostly from skin and annexes.

Regarding to the antifungal susceptibility of malbranchea-like fungi, limited data are available. However, in a previous study on onychomycosis-causing strains of Auxarthron ostraviense and Auxarthron umbrinum (transferred to the genus Malbranchea in the present study) reduced susceptibility to AMB, ITC and PSC was reported, but a high susceptibility to TRB was observed (Hubka et al. 2013). Another study (Gupta \& Kohli 2003) showed that strains of Arachnomyces nodosetosus (syn. Onychocola canadensis) where highly susceptible to cicciclopirox and TRB. Our results are consistent with such previous studies, but we also demonstrated the enhanced susceptibility of the malbranchea tike fungi to the echinocandins. 


\section{List Of Abbreviations}

$5-\mathrm{FC}=5$-fluorocytosine

$\mathrm{AFG}=$ anidulafungin

$\mathrm{AMB}=$ amphotericin $\mathrm{B}$

BCP-MS-G = bromocresol purple milk solids glucose agar

$\mathrm{BI}=$ Bayesian-inference

BLAST = Basic Local Alignment Search Tool

BS $=$ bootstrap support

$\mathrm{CFG}=$ caspofungin

$\mathrm{CLSI}=$ Clinical and Laboratory Standards Institute

DNA = deoxyribonucleic acid

$\mathrm{FLC}=$ fluconazole

$\mathrm{ITC}=$ itraconazole

ITS = ribosomal internal transcribed spacers

LSU = large sub unit of the ribosomal genes

MEC $=$ Minimal Effective Concentrations

MFG = micafungin

MIC = Minimal Inhibitory Concentrations

$\mathrm{ML}=$ maximum-likelihood

$\mathrm{MLI}=$ maximum level of identity

$O A=$ oatmeal agar

PDA = potato dextrose agar

$\mathrm{PP}=$ posterios probability

PSC = posaconazole

PYE $=$ phytone yeast extract agar

SDA = Sabouraud dextrose agar 
SEM = scanning electron microscopy

TOTM = test opacity tween medium

TRB $=$ terbinafine

TreeBASE = a repository of user-submitted phylogenetic trees and data used to build them

USA = United States of America

UTHSCA = University of Texas Health Science Centre at San Antonio

$\mathrm{VRC}=$ voriconazole

\section{Declarations}

\section{Ethics approval and consent to participate}

Not applicable.

\section{Adherence to national and international regulations}

The authors confirm that this manuscript respects the Nagoya Protocol to the Convention on Biological Diversity.

Consent for publication

Not applicable.

\section{Availability of data and material}

All data generated or analysed during this study are included in this published article.

\section{Competing interests}

The authors declare that they have no competing interests.

\section{Funding}

The authors are indebted to the Instituto de Ciencia, Tecnología e Innovación (Mexico) and the Consejo Nacional de Ciencia y Tecnología (Mexico) for the scholarship 440135 with scholar 277137. This work was supported by the Spanish Ministerio de Economía y Competitividad, grant CGL2017-88094-P. APC is the recipient of a FI fellowship from Generalitat de Catalunya (Spain).

\section{Authors' contributions}

ER-A performed all the experimental work, performing their phenotypic characterization, as well as the DNA extraction and purification, gene sequencing and data processing for phylogenetic analysis, being one of the major contributors of this manuscript. PC-A, performed and supervised with ER-A all the Antifungal susceptibility testing, reviewed the draft and writing part of "Materials and methods". AMS, because their experience on fungi belonging to Onygenales, supervised all steps of the experimental work by ER-A, collaborating in the description of the novel 
fungi and in the writing of chapters "Introduction" and "Discussion", reviewing of the draft several times. WN, carried out the collection and morphological identification of the analysed strains, and reviewing the draft. JG contributed actively in the identification and taxonomy of the fungal strains, and reviewed the draft several times. JFC-L supervised the nucleotide sequence alignment and phylogenetic reconstruction, took the pictures that appear in the figures, contributed actively in the identification and taxonomy of the fungal strains, gave useful suggestions to write the manuscript and reviewed several times the draft. All authors read and approved the final manuscript.

\section{Acknowledgements}

The authors are indebted to Mr. Phil Hoddy for editing and proofreading the final text. We also thank to Patricia Navarro for supporting in Antifungal susceptibility testing.

\section{References}

Benda TJ, Corey JP (1994). Malbranchea pulchella fungal sinusitis. Otolaryngology - Head and Neck Surgery 110:501-504.

Brasch J, Beck-Jendroscheck V, Voos K, Y Andrey, Stchigel AM et al (2017). Xanthothecium peruvianum isolated from human stratum corneum: A case report, characterization and short review that suggest emendation of Arachnomyces peruvianus. Mycoses 60:469-476.

Cain RF (1957). Studies of coprophilous ascomycetes. IV. Species from the Hudson bay area. Canadian Journal of Botany 35:255-268.

Campbell CK, Johnson EM, Warnock DW (1997). Nail infection caused by Onychocola canadensis: report of the first four British cases. Journal of Medical and Veterinary Mycology 35:423-425.

Carmichael JW, Kraus HJ (1959). The cattle ringworm fungus, Trichophyton verrucosum, in Alberta. Alberta Medical Bulletin 24:201-203.

Christensen WB (1946). Urea decomposition as means of differentiating Proteus and Paracolon cultures from each other and from Salmonella and Shigella types. Journal of Bacteriology 52:461-466.

CLSI (2017). Reference method for broth dilution antifungal susceptibility testing of filamentous fungi, 3rd ed. CLSI standard M38. Clinical and Laboratory Standards Institute, Wayne, PA, USA.

Contet-Audonneau N, Schmutz JL, Basile AM, De Bièvre C (1997). A new agent of onychomycosis in the elderly: Onychocola canadensis. European Journal of Dermatology 7:115-117.

Cooney DG, Emerson R (1964) Thermophilic fungi. Freeman WH and Co., San Francisco, USA.

Crous PW, Gams W, Stalpers JA, Robert V, Stegehuis G (2004). MycoBank: an online initiative launch mycology into the 21st century. Studies in Mycology 50:19-22.

Crous PW, Wingfield MJ, Guarro J, Cheewangkoon R, van der Bank M et al (2013). Fungal Planet description sheets: 154-213. Persoonia 31:188-296. 
Currah RS (1985). Taxonomy of the Onygenales: Arthrodermataceae, Gymnoascaceae, Myxotrichaceae and Onygenaceae. Mycotaxon 24:1-216.

Currah RS (1994). Peridial morphology and evolution in the protunicate ascomycetes. In Ascomycetes systematics. Hawksworth DL (ed.). Plenum Press, New York, USA.

de Hoog GS, Dukik K, Monod M, Packeu A, Stubbe D et al (2017). Toward a novel multilocus phylogenetic taxonomy for the dermatophytes. Mycopathologia 182:5-31.

Doveri F, Pecchia S, Vergara M, Sarrocco S, Vannacci G (2012). A comparative study of Neogymnomyces virgineus, a new keratinolytic species from dung, and its relationships with the Onygenales. Fungal Diversity 52:13-34.

Dukik K, Muñoz JF, Jiang Y, Feng P, Sigler L et al (2017). Novel taxa of thermally dimorphic systemic pathogens in the Ajellomycetaceae (Onygenales). Mycoses 60:296-309.

Durdu M, Kandemir H, Ilkit M, de Hoog S (2019). Changing concepts and current definition of Majocchi'sg Granuloma. Mycopathologia 185:187-192.

Erbagci Z, Balci I, Erkiliç S, Zer Y, Inci R (2002). Cutaneous hyalohyphomycosis and onychomycosis caused by Onychocola canadensis: Report of the first case from Turkey. The Journal of Dermatology 29:522-528.

Gibas CF, Sigler L, Currah RS (2004). Mating patterns and ITS sequences distinguish the sclerotial species Arachnomyces glareosus sp. nov. and Onychocola sclerotica. Studies in Mycology 50:525-531.

Gibas CF, Sigler L, Summerbell R, Hofstader S, Gupta A (2002). Arachnomyces kanei (anamorph Onychocola kanei) sp. nov., from human nails. Medical Mycology 40:573-580.

Giraldo A, Sutton D, Gené J et al. (2013). Rare arthroconidial fungi in clinical samples: Scytalidium cuboideum and Arthropsis hispanica. Mycopathologia 175:115-121.

Govind A, L'Etoile N, Vasquez G (2017). The first reported case of Majocchi's granuloma with Malbranchea sp. in a immunocompetent patient. Case Reports in Infectious Diseases ID 9196528.

Guarro J, Gené J, De Vroey CH (1993). Studies on keratinophilic fungi. I. A new Malbranchea from Sulawesi. Mycotaxon 48:471-476.

Gupta AK, Gupta G, Jain HC, Lynde CW, Foley K et al (2016). The prevalence of unsuspected onychomycosis and its causative organism in a multicenter canadian sample of 30000 patients visiting physicians's offices. Journal of the European Academy of Dermatology and Venereology 30:1567-1572.

Gupta AK, Horgan-Bell CB, Summerbell RC (1998). Onychomycosis associated with Onychocola canadensis: ten case reports and a review of the literature. Journal of the Academy of Dermatology 39:410-417.

Gupta AK, Kohli Y (2003). In vitro susceptibility testing of ciclopirox, terbinafine, ketoconazole and itraconazole against dermatophytes and non-dermatophytes, and in vitro evaluation of combination antifungal activity. British Journal of Dermatology 149:296-305.

Hawksworth DL, Kirk PM, Sutton BC, Pegler DN (1995). Ainsworth \& Bisby`s Dictionary of the Fungi. 8th edition. CAB International, Wallingford. 
Hirooka Y, Tanney JB, Nguyen H, Seifert K (2016). Xerotolerant fungi in house dust: taxonomy of Spiromastix, Pseudospiromastix and Sigleria gen nov. in Spiromastigaceae (Onygenales, Eurotiomycetes). Mycologia 108:135156.

Hubka V, Dobiasova S, Lyskova P, Mallátová N, Chlebkova J et al (2013). Auxarthron ostraviense sp. nov., and A. umbrinum associated with non-dermatophytic onychomycosis. Medical Mycology 51:614-624.

Hubálek Z (2000). Keratinophilic fungi associated with free-living mammals and birds. Revista Iberoamericana de Micología 17:93-103.

Järv H (2015). Onychomycosis caused by Onychocola canadensis: the first report in Estonia and lessons to learn. Mycoses 58:113-117.

Jiang Y, Dukik K, Muñoz JF, Sigler L, Schwartz I et al (2018). Phylogeny, ecology and taxonomy of systemic pathogens and their relatives in Ajellomycetaceae(Onygenales): Blastomyces, Emergomyces, Emmonsia, Emmonsiellopsis. Fungal Diversity 90:245-291.

Kane J, Smitka C (1978). Early detection and identification of Trichophyton verrucosum. Journal of Clinical Microbiology 8:740-747.

Kane J, Summerbell RC, Sigler L, Krajden S, Land G (1997). Laboratory handbook of dermatophytes: A clinical guide and laboratory manual of dermatophytes and other filamentous fungi from skin, hair and nails. Belmont CA: Star Publishing Company. 344 pp.

Koenig H, Ball C, de Bievre C (1997). First european cases of onychomycosis caused by Onychocola canadensis. Journal of Medical and Veterinary Mycology 35:71-72.

Kornerup A, Wanscher JH (1978). Methuen handbook of colour. 3rd edition. Methuen, London.

Kuehn HH, Orr GF (1962). A new genus of Gymnoascaceae. Mycologia 54:160-167.

Kuehn HH, Orr GF, Ghosh GR (1964). Pathological implications of the Gymnoascaceae. Mycophatologia et Mycologia Applicata 24:35-46.

Llovo J, Prieto E, Vazquez H, Muñoz A (2002). Onychomycosis due to Onychocola canadensis: report of the first two Spanish cases. Medical Mycology 40:209-212.

Lyskova P (2007). Saprophytic microscopic fungi and dermatophytes accompanying infections of the skin and nails of patients in the Moravian-Silesian region. Czech Mycology 59:125-137.

Malloch D, Cain RF (1970) The genus Arachnomyces. Canadian Journal of Botany 48:839-845.

O’Donoghue NB, Moore MK, Creamer D (2003). Onychomycosis due to Onychocola canadensis. Clinical and Experimental Dermatology 28:283-284.

Orr GF, Kuehn HH, Plunkett OA (1963). A new genus of the Gymnoascaceae with swollen peridial septa. Canadian Journal of Botany 42:1439-1456. 
Orr GF, Kuehn HH (1972). Notes on Gymnoascaceae II. Some Gymnoascaceae and keratinophilic fungi from Utah. Mycologia 64:55-72.

Pan S, Sigler L, Cole GT (1994). Evidence for a phylogenetic connection between Coccidioides immitis and Uncinocarpus reesii (Onygenaceae). Microbiology 140:1481-1494.

Patil MS, Pawar AB (1987). Plectomycetes from Maharashtra II. Geobios new Reports 6:194-196.

Rehner SA, Samuels GJ (1994). Taxonomy and phylogeny of Gliocladium analysed from nuclear large subunit ribosomal DNA sequences. Mycological Research 98:625-634.

Rizzo L, Sutton DA, Wiederhold NP, Thompson EH, Friedman R et al (2014). Isolation and characterisation of the fungus Spiromastix asexualis sp. nov. from discospondylitis in German Shepherd dog, and review of Spiromastix with the proposal of the new order Spiromastixales (Ascomycota). Mycoses 57:419-428.

Saccardo PA (1882). Fungi Gallici. Series IV. Michelia 2:583-648.

Saccardo PA (1908). Notae mycologicae Ser. X. Annales Mycologici 6:553-516.

Saccardo PA, Trotter A (1913). Sylloge fungorum omnium hucusque cognitorum 22:1240.

Samson RA, Houbraken J, Thrane U, Frisvad JC, Andersen B (2010) Food and indoor fungi. CBS-KNAW Fungal Biodiversity Centre, Utrecht.

Sarrocco S, Diquattro S, Baroncelli R, Cimmino A, Evidente A et al (2015). A polyphasic contribution to the knowledge of Auxarthron (Onygenaceae). Mycological Progress 14:112.

Sharma R, Shouche YS (2019). Diversity of onygenalean fungi in keratin-rich habitats of Maharashtra (India) and description of three novel taxa. Mycopathologia 185:67-85.

Sigler L, Abbott SP, Woodgyer AJ (1994). New records of nail and skin infection due to Onychocola canadensis and description of its teleomorph Arachnomyces nodosetosus sp. nov. Journal of Medical and Veterinary Mycology $32: 275-285$.

Sigler L, Carmichael JW (1976). Taxonomy of Malbranchea and some other Hyphomycetes with arthroconidia. Mycotaxon 4:349-488.

Sigler L, Congly H (1990). Toenail infection caused by Onychocola canadensis gen. et sp. nov. Journal of Medical and Veterinary Mycology 28:405-417.

Sigler L, Hambleton S, Flis AL, Paré JA (2002). Auxarthron teleomorphs for Malbranchea filamentosa and Malbranchea albolutea and relationships within Auxarthron. Studies in Mycology 47:111-122.

Slifkin M (2000). Tween 80 opacity test responses of various. Candida species. Journal of Clinical Microbiology 38:4626-4628.

Solé M, Cano J, Guarro J (2002). Molecular phylogeny of Amauroascus, Auxarthron, and morphologically similar onygenalean fungi. Mycological Research 106:388-396. 
Stchigel AM, Sutton DA, Cano-Lira JF, Wiederhold N, Guarro J (2017). New species Spiromastigoides albida from a lung biopsy. Mycopathologia 182:967-978.

Stuchlík D, Mencl K, Hubka V, Skorepova M (2011). Fungal melanonychia caused by Onychocola canadensis: first record of nail infections due to Onychocola in the Czech Republic. Czech Mycology 63:83-91

Sugiyama M, Mikawa T (2001). Phylogenetic analysis of the non-pathogenic genus Spiromatix (Onygenaceae) and related onygenalean taxa based on large subunit ribosomal DNA sequences. Mycoscience 42:413-421.

Sugiyama M, Okawa A Mikawa T (1999). Molecular phylogeny of onygenalean fungi based on small subunit ribosomal DNA (SSU rDNA) sequences. Mycoscience 40:251-258.

Sugiyama M, Summerbell RC, Mikawa T (2002). Molecular phylogeny of onygenalean fungi based on small subunit (SSU) and large subunit (LSU) ribosomal DNA sequences. Studies in Mycology 47:5-23.

Sun B, Zhou Y, Chen AJ, Houbraken J (2019). Phylogeny and a new species of the genus Arachnomyces (Arachnomycetaceae). Phytotaxa 394:89-97.

Turland NJ, Wiersema JH, Barrie FR, Greuter W, Hawksworth DL et al (eds.) (2018). International Code of Nomenclature for algae, fungi, and plants (Shenzhen Code) adopted by the Nineteenth International Botanical Congress Shenzhen, China, July 2017. Regnum Vegetabile 159. Glashütten: Koeltz Botanical Books.

Uchiyama S, Kamiya S, Udagawa S (1995). Spiromastix saturnispora, a new species from Indonesian soil. Mycoscience 36:353-357.

Udagawa S, Uchiyama S (1999). Taxonomic studies on new or critical fungi of non-pathogenic Onygenales 1. Mycoscience 40:277-290.

Untereiner WA, Scott JA, Naveae FA, Currah S, Bachewich J (2002). Phylogeny of Ajellomyces, Polytolypa and Spiromastix (Onygenaceae) inferred from rDNA sequence and non-molecular data. Studies in Mycology 47:25-35.

Valenzuela-Lopez N, Cano-Lira JF, Guarro J, Sutton D, Wiederhold N et al (2018). Coelomycetous Dothideomycetes with emphasis on the families Cucurbitariaceae and Didymellaceae. Studies in Mycology 90:1-69.

van Oorschot CA, de Hoog GS (1984). Some hyphomycetes with thallic conidia. Mycotaxon 20:129-132.

Vilgalys R, Hester M (1990). Rapid genetic identification and mapping of enzymatically amplified ribosomal DNA from several Cryptococcus species. Journal of Bacteriology 172:4238-4246.

White T, Bruns T, Lee S, Taylor J (1990). Amplification and direct sequencing of fungal ribosomal RNA genes for phylogenetics. In: Innis M, Gelfand D, Shinsky J, White T (eds) PCR Protocols: a guide to methods and applications, Academic Press, San Diego.

Yahaya H, Taura D, Aliyu IA, Bala JA, Yunusa I et al (2015). Spectrum of opportunistic mould infections in suspected pulmonary tuberculosis (TB) patients. International Journal of Microbiology and Application 2:6-11.

Zhan P, Dukik K, Li D, Sun J, Stielow B et al (2018). Phylogeny of dermatophytes with genomic character evaluation of clinically distinct Trichophyton rubrum and T. violaceum. Studies in Mycology 89:153-175. 


\section{Tables}

Table 1. DNA barcodes used to build the phylogenetic tree. 


\begin{tabular}{|c|c|c|c|c|}
\hline \multirow[t]{2}{*}{ Species } & \multirow[t]{2}{*}{ Strains ${ }^{1}$} & \multicolumn{2}{|c|}{ GenBank accession $\#^{2}$} & \multirow{2}{*}{$\begin{array}{l}\text { Geographic origin and } \\
\text { source }\end{array}$} \\
\hline & & $\mathrm{ITS}^{3}$ & $\mathrm{LSU}^{3}$ & \\
\hline Ajellomyces capsulatus & UAMH $3536^{\top}$ & AF038354 & AF038354 & $\begin{array}{l}\text { Alberta, Canada; } \\
\text { woman, } 25 \text {-years-old, } \\
\text { biopsy of right middle } \\
\text { lobe lung }\end{array}$ \\
\hline Amauroascus niger & ATCC 22339 & MH869547 & AY176706 & California, U.S.A.; soil \\
\hline Amauroascus purpureus & IFO $32622^{\top}$ & AJ271564 & AY176707 & Japan; soil \\
\hline $\begin{array}{l}\text { Amauroascus volatilis- } \\
\text { patellis }\end{array}$ & CBS $249.72^{\top}$ & MH860467 & MH872189 & Utah, U.S.A.; soil \\
\hline Aphanoascus mephitalis & ATCC 22144 & MH859941 & AY176725 & $\begin{array}{l}\text { Ontario, Canada; wolf } \\
\text { dung }\end{array}$ \\
\hline Arachniotus verruculosus & CBS 655.71 & NR_145221 & AB040684 & Utah, U.S.A.; soil \\
\hline $\begin{array}{l}\text { Arachnomyces } \\
\text { bostrychodes sp. nov. }\end{array}$ & $\begin{array}{l}\text { UTHSCSA DI18-91 = FMR } \\
17685=\text { CBS } 146926^{\top}\end{array}$ & LR701765 & LR701766 & $\begin{array}{l}\text { Texas, U.S.A.; human } \\
\text { scalp }\end{array}$ \\
\hline Arachnomyces glareosus & CBS $116129^{\top}$ & AY624316 & FJ358273 & $\begin{array}{l}\text { Alberta, Canada; man, } \\
30 \text {-years-old, thumb } \\
\text { nail }\end{array}$ \\
\hline $\begin{array}{l}\text { Arachnomyces } \\
\text { graciliformis sp. nov. }\end{array}$ & $\begin{array}{l}\text { UTHSCSA DI18-97 = FMR } \\
17691=\text { CBS } 146927^{\top}\end{array}$ & LR743667 & LR743668 & $\begin{array}{l}\text { Massachusetts, U.S.A.; } \\
\text { animal bone }\end{array}$ \\
\hline Arachnomyces gracilis & UAMH $9756^{\top}$ & AY123779 & - & $\begin{array}{l}\text { Uganda; termitarium } \\
\text { soil }\end{array}$ \\
\hline Arachnomyces jinanicus & CGMCC3.14173 ${ }^{\top}$ & KY440749 & KY440752 & $\begin{array}{l}\text { Jinan, China; pig farm } \\
\text { soil }\end{array}$ \\
\hline Arachnomyces kanei & UAMH $5908^{\top}$ & AY123780 & - & $\begin{array}{l}\text { Toronto, Canada; } \\
\text { human nail }\end{array}$ \\
\hline Arachnomyces minimus & CBS $324.70^{\top}$ & AY123783 & FJ358274 & $\begin{array}{l}\text { Ontario, Canada; } \\
\text { decaying wood }\end{array}$ \\
\hline Arachnomyces nitidus & UAMH 10536 & - & AB075351 & Israel; twigs \\
\hline $\begin{array}{l}\text { Arachnomyces } \\
\text { nodosetosus }\end{array}$ & CBS $313.90^{\top}$ & AY123784 & AB053452 & $\begin{array}{l}\text { Saskatchewan, } \\
\text { Canada; woman, 67- } \\
\text { years-old, } \\
\text { onychomycosis }\end{array}$ \\
\hline $\begin{array}{l}\text { Arachnomyces } \\
\text { peruvianus }\end{array}$ & CBS $112.54^{\top}$ & MF572315 & MH868792 & $\begin{array}{l}\text { Peru; Globodera } \\
\text { rostochiensis cyst }\end{array}$ \\
\hline Arachnomyces pilosus & CBS $250.93^{\top}$ & MF572320 & MF572325 & $\begin{array}{l}\text { Catalonia, Spain; river } \\
\text { sediment }\end{array}$ \\
\hline $\begin{array}{l}\text { Arachnomyces } \\
\text { scleroticus }\end{array}$ & UAMH $7183^{\top}$ & AY123785 & - & $\begin{array}{l}\text { Sulawesi, Indonesia; } \\
\text { poultry farm soil }\end{array}$ \\
\hline Arthroderma curreyi & CBS $353.66^{\top}$ & MH858822 & MH870459 & UK; unknown \\
\hline Arthroderma onychocola & CBS $132920^{\top}$ & KT155794 & KT155124 & Prague, Czech \\
\hline
\end{tabular}


Republic; human nail

\begin{tabular}{|c|c|c|c|c|}
\hline Ascosphaera apis & CBS 252.32 & - & AY004344 & $\begin{array}{l}\text { København, Denmark; } \\
\text { Apis mellifera }\end{array}$ \\
\hline Ascosphaera subglobosa & A.A. Wynns $5004(C)^{\top}$ & NR_137060 & HQ540517 & $\begin{array}{l}\text { Utah, U.S.A.; pollen } \\
\text { provisions of } \\
\text { Megachile rotundata }\end{array}$ \\
\hline $\begin{array}{l}\text { Auxarthronopsis } \\
\text { bandhavgarhensis }\end{array}$ & $\mathrm{NFCCI} 2185^{\top}$ & HQ164436 & NG_057012 & $\begin{array}{l}\text { Bandhavgarh, India; } \\
\text { soil }\end{array}$ \\
\hline $\begin{array}{l}\text { Auxarthronopsis } \\
\text { guizhouensis }\end{array}$ & CGMCC3.17910 ${ }^{\top}$ & KU746668 & KU746714 & Guizhou, China; air \\
\hline Blastomyces percusus & CBS $139878^{\top}$ & NR_153647 & KY195971 & $\begin{array}{l}\text { Israel; human } \\
\text { granulomatous lesions }\end{array}$ \\
\hline Canomyces reticulatus & $\operatorname{MCC} 1486^{\top}$ & MK340501 & MK340502 & $\begin{array}{l}\text { Maharashtra, India; } \\
\text { soil }\end{array}$ \\
\hline $\begin{array}{l}\text { Chrysosporium } \\
\text { keratinophilum }\end{array}$ & CBS 392.67 & MH859002 & AY176730 & New Zealand; soil \\
\hline Chrysosporium tropicum & MUCL $10068^{\top}$ & MH858134 & AY176731 & $\begin{array}{l}\text { Guadalcanal, Solomon } \\
\text { islands; woollen } \\
\text { overcoat }\end{array}$ \\
\hline Currahmyces indicus & $\operatorname{MCC} 1548^{\top}$ & MK340498 & MK340499 & $\begin{array}{l}\text { Maharashtra, India; } \\
\text { hen resting area }\end{array}$ \\
\hline $\begin{array}{l}\text { Currahmyces sparsispora } \\
\text { sp. nov. }\end{array}$ & $\begin{array}{l}\text { UTHSCSA DI18-89 = FMR } \\
17683=\text { CBS } 146929^{\mathrm{T}}\end{array}$ & LR723272 & LR723273 & $\begin{array}{l}\text { Florida, U.S.A.; human } \\
\text { sputum }\end{array}$ \\
\hline Gymnoascus reesii & CBS 410.72 & MH860507 & MH872224 & California, U.S.A.; soil \\
\hline $\begin{array}{l}\text { Helicoarthrosporum } \\
\text { mellicola }\end{array}$ & CBS $143838^{\top}$ & LR761645 & LT906535 & Granada, Spain; honey \\
\hline $\begin{array}{l}\text { Helicoarthrosporum } \\
\text { mellicola }\end{array}$ & FMR 15673 & LR761646 & LT978462 & Valencia, Spain; honey \\
\hline Malbranchea albolutea & $\begin{array}{l}\text { UTHSCSA DI18-85 = FMR } \\
17679\end{array}$ & LR701834 & LR701835 & $\begin{array}{l}\text { Texas, U.S.A.; human } \\
\text { BAL }\end{array}$ \\
\hline Malbranchea albolutea & $\begin{array}{l}\text { UTHSCSA DI18-95 = FMR } \\
17689\end{array}$ & LR701836 & LR701837 & $\begin{array}{l}\text { Texas, U.S.A.; human } \\
\text { BAL }\end{array}$ \\
\hline Malbranchea albolutea & CBS $125.77^{\top}$ & MH861039 & MH872808 & Utah, U.S.A.; soil \\
\hline Malbranchea aurantiaca & $\begin{array}{l}\text { UTHSCSA DI18-94 = FMR } \\
17688\end{array}$ & LR701824 & LR701825 & $\begin{array}{l}\text { California, U.S.A.; } \\
\text { animal }\end{array}$ \\
\hline Malbranchea aurantiaca & $\begin{array}{l}\text { UTHSCSA DI18-88 = FMR } \\
17682\end{array}$ & LR701826 & LR701827 & $\begin{array}{l}\text { Texas, U.S.A.; animal } \\
\text { skin lesion }\end{array}$ \\
\hline Malbranchea aurantiaca & CBS $127.77^{\top}$ & NR_157447 & AB040704 & $\begin{array}{l}\text { Utah, U.S.A.; culture } \\
\text { contaminant }\end{array}$ \\
\hline $\begin{array}{l}\text { Malbranchea } \\
\text { californiensis }\end{array}$ & ATCC $15600^{\top}$ & MH858121 & NG_056947 & $\begin{array}{l}\text { California, U.S.A.; dung } \\
\text { of pack rat }\end{array}$ \\
\hline $\begin{array}{l}\text { Malbranchea } \\
\text { chrysosporioidea }\end{array}$ & CBS $128.77^{\top}$ & AB361632 & AB359413 & Arizona, U.S.A.; soil \\
\hline
\end{tabular}




\begin{tabular}{|c|c|c|c|c|}
\hline Malbranchea circinata & ATCC $34526^{\top}$ & MN627784 & MN627782 & Utah, U.S.A.; soil \\
\hline Malbranchea conjugata & $\begin{array}{l}\text { UTHSCSA DI18-105 = } \\
\text { FMR } 17699\end{array}$ & LR701828 & LR701829 & $\begin{array}{l}\text { Florida, U.S.A.; human } \\
\text { lung tissue }\end{array}$ \\
\hline Malbranchea conjugata & $\begin{array}{l}\text { UTHSCSA DI18-103 = } \\
\text { FMR } 17697\end{array}$ & LR701830 & LR701831 & $\begin{array}{l}\text { Texas, U.S.A.; human } \\
\text { BAL }\end{array}$ \\
\hline Malbranchea conjugata & CBS 247.58 & NR_121475 & HF545313 & Arizona, U.S.A.; soil \\
\hline Malbranchea dendritica & CBS $131.77^{\top}$ & AY177310 & AB359416 & Utah, U.S.A.; soil \\
\hline Malbranchea filamentosa & CBS $581.82^{\top}$ & NR_111136 & AB359417 & Argentina; soil \\
\hline Malbranchea flava & CBS $132.77^{\top}$ & AB361633 & AB359418 & California, U.S.A.; soil \\
\hline Malbranchea flavorosea & ATCC $34529^{\mathrm{T}}$ & NR 158362 & AB359419 & California, U.S.A.; soil \\
\hline Malbranchea flocciformis & $\begin{array}{l}\text { UTHSCSA DI18-104 = } \\
\text { FMR } 17698\end{array}$ & LR701822 & LR701823 & $\begin{array}{l}\text { Texas, U.S.A.; human } \\
\text { skin }\end{array}$ \\
\hline Malbranchea flocciformis & CBS $133.77^{\top}$ & AB361634 & AB359420 & France; saline soil \\
\hline Malbranchea fulva & CBS $135.77^{\top}$ & NR_157444 & AB359422 & Utah, U.S.A.; air \\
\hline $\begin{array}{l}\text { Malbranchea } \\
\text { gymnoascoides sp. nov. }\end{array}$ & $\begin{array}{l}\text { UTHSCSA DI18-87 = FMR } \\
17681=\text { CBS } 146930^{\top}\end{array}$ & LR701757 & LR701758 & $\begin{array}{l}\text { Texas, U.S.A.; human } \\
\text { BAL }\end{array}$ \\
\hline Malbranchea kuehnii & CBS $539.72^{\top}$ & NR_103573 & NG_056928 & Unkown; dung \\
\hline Malbranchea longispora & FMR $12768^{\top}$ & HG326873 & HG326874 & Beija, Portugal; soil \\
\hline $\begin{array}{l}\text { Malbranchea } \\
\text { multiseptata sp. nov. }\end{array}$ & $\begin{array}{l}\text { UTHSCSA DI18-101 = } \\
\text { FMR } 17695=\text { CBS } \\
146931^{\top}\end{array}$ & LR701759 & LR701760 & $\begin{array}{l}\text { Texas, U.S.A.; human } \\
\text { BAL }\end{array}$ \\
\hline Malbranchea ostraviense & CBS $132919^{\top}$ & NR_121474 & - & $\begin{array}{l}\text { Ostrava, Czech } \\
\text { Republic; fingernail } \\
\text { sample }\end{array}$ \\
\hline Malbranchea pulchella & CBS 202.38 & AB361638 & AB359426 & Italy; unknown \\
\hline $\begin{array}{l}\text { Malbranchea stricta sp. } \\
\text { nov. }\end{array}$ & $\begin{array}{l}\text { UTHSCSA DI18-86 = FMR } \\
17680=\text { CBS } 146932^{\top}\end{array}$ & LR701638 & LR701639 & $\begin{array}{l}\text { Florida, U.S.A.; human } \\
\text { nail }\end{array}$ \\
\hline Malbranchea sp.* & CBS 319.61 & MH858065 & MH869635 & California, U.S.A.; soil \\
\hline Malbranchea umbrina & $\begin{array}{l}\text { UTHSCSA DI18-106 = } \\
\text { FMR } 17700\end{array}$ & LR701814 & LR701815 & $\begin{array}{l}\text { Colorado, U.S.A.; } \\
\text { human BAL }\end{array}$ \\
\hline Malbranchea umbrina & $\begin{array}{l}\text { UTHSCSA DI18-107 = } \\
\text { FMR } 17701\end{array}$ & LR701816 & LR701817 & $\begin{array}{l}\text { Colorado, U.S.A.; } \\
\text { human sinus }\end{array}$ \\
\hline Malbranchea umbrina & $\begin{array}{l}\text { UTHSCSA DI18-100 = } \\
\text { FMR } 17694\end{array}$ & LR701818 & LR701819 & $\begin{array}{l}\text { Baltimore, U.S.A.; } \\
\text { human wound }\end{array}$ \\
\hline Malbranchea umbrina & $\begin{array}{l}\text { UTHSCSA DI18-99 = FMR } \\
17693\end{array}$ & LR701820 & LR701821 & $\begin{array}{l}\text { Washington DC, U.S.A.; } \\
\text { human nail }\end{array}$ \\
\hline Malbranchea umbrina & CBS $105.09^{\mathrm{T}}$ & MH854591 & MH866116 & UK; soil \\
\hline
\end{tabular}




\begin{tabular}{|c|c|c|c|c|}
\hline Malbranchea umbrina & CBS 226.58 & MH857765 & MH869296 & Unknown \\
\hline Malbranchea umbrina & CBS 261.52 & MH857026 & MH868556 & UK; soil \\
\hline Malbranchea zuffiana & $\begin{array}{l}\text { UTHSCSA DI18-96 = FMR } \\
17690\end{array}$ & LR701832 & LR701833 & $\begin{array}{l}\text { Washington DC, U.S.A.; } \\
\text { human wound }\end{array}$ \\
\hline Malbranchea zuffiana & CBS $219.58^{\top}$ & MH869293 & AY176712 & $\begin{array}{l}\text { Texas, U.S.A.; prairie } \\
\text { dog lung }\end{array}$ \\
\hline Nannizziopsis guarroi & CBS $124553^{\top}$ & MH863384 & MH874904 & $\begin{array}{l}\text { Barcelona, Spain; } \\
\text { iguana skin }\end{array}$ \\
\hline Nannizziopsis vriesii & ATCC $22444^{\top}$ & AJ131687 & AY176715 & $\begin{array}{l}\text { The Netherlands; } \\
\text { Ameiva (lizard) skin } \\
\text { and lung }\end{array}$ \\
\hline $\begin{array}{l}\text { Neogymnomyces } \\
\text { demonbreunii }\end{array}$ & CBS 427.70 & AJ315842 & AY176716 & $\begin{array}{l}\text { Missouri, U.S.A.; } \\
\text { unknown }\end{array}$ \\
\hline Onychocola canadensis & CBS 109438 & - & KT154998 & $\begin{array}{l}\text { Italy; nail and skin } \\
\text { scrapings }\end{array}$ \\
\hline $\begin{array}{l}\text { Paracoccidioides } \\
\text { brasiliensis }\end{array}$ & UAMH $8037^{\top}$ & AF038360 & AF038360 & $\begin{array}{l}\text { Alberta, Canada; man, } \\
59 \text {-years-old, lung } \\
\text { biopsy }\end{array}$ \\
\hline Pseudoarthropsis cirrhata & CBS $628.83^{\top}$ & - & NG_060792 & $\begin{array}{l}\text { Schiphol, The } \\
\text { Netherlands; wall } \\
\text { sample }\end{array}$ \\
\hline $\begin{array}{l}\text { Pseudoarthropsis } \\
\text { crassispora sp. nov. }\end{array}$ & $\begin{array}{l}\text { UTHSCSA DI18-98 = FMR } \\
17692=\text { CBS 146928 }\end{array}$ & LR701763 & LR701764 & $\begin{array}{l}\text { Minnesota, U.S.A.; } \\
\text { human BAL }\end{array}$ \\
\hline $\begin{array}{l}\text { Pseudomalbranchea } \\
\text { gemmata gen. nov. et sp. } \\
\text { nov. }\end{array}$ & $\begin{array}{l}\text { UTHSCSA DI18-90 = FMR } \\
17684=\text { CBS } 146933^{\top}\end{array}$ & LR701761 & LR701762 & $\begin{array}{l}\text { Florida, U.S.A.; human } \\
\text { BAL }\end{array}$ \\
\hline $\begin{array}{l}\text { Pseudospiromastix } \\
\text { tentaculata }\end{array}$ & CBS 184.9210536 & AY527406 & LN867603 & Hiram, Somalia; soil \\
\hline Renispora flavissima & CBS $708.79^{\top}$ & AF299348 & AY176719 & $\begin{array}{l}\text { Kansas, U.S.A.; soil in } \\
\text { barn housing Myotis } \\
\text { velifer }\end{array}$ \\
\hline $\begin{array}{l}\text { Spiromastigoides } \\
\text { alatosporus }\end{array}$ & CBS $457.73^{\top}$ & MH860740 & AB075342 & $\begin{array}{l}\text { Madras, India; Vigna } \\
\text { sinensis rhizosphere }\end{array}$ \\
\hline Spiromastigoides albina & CBS $139510^{\top}$ & LN867606 & LN867602 & $\begin{array}{l}\text { Texas, U.S.A.; human } \\
\text { lung biopsy }\end{array}$ \\
\hline $\begin{array}{l}\text { Spiromastigoides } \\
\text { asexualis }\end{array}$ & CBS $136728^{\top}$ & KJ880032 & LN867603 & $\begin{array}{l}\text { Phoenix, U.S.A.; } \\
\text { discospondylitis } \\
\text { material from a } \\
\text { German shepherd dog }\end{array}$ \\
\hline Spiromastigoides curvata & JCM $11275^{\top}$ & KP119631 & KP119644 & $\begin{array}{l}\text { México; contaminant } \\
\text { of a strain of } \\
\text { Histoplasma } \\
\text { capsulatum }\end{array}$ \\
\hline Spiromastigoides frutex & CBS $138266^{\top}$ & KP119632 & KP119645 & $\begin{array}{l}\text { Nayarit, Mexico; house } \\
\text { dust, rental studio }\end{array}$ \\
\hline
\end{tabular}




\begin{tabular}{|c|c|c|c|c|}
\hline $\begin{array}{l}\text { Spiromastigoides } \\
\text { geomycoides sp. nov. }\end{array}$ & $\begin{array}{l}\text { UTHSCSA DI18-92 = FMR } \\
17686\end{array}$ & LR701769 & LR701770 & $\begin{array}{l}\text { Minnesota, U.S.A.; } \\
\text { human blood }\end{array}$ \\
\hline $\begin{array}{l}\text { Spiromastigoides } \\
\text { geomycoides sp. nov. }\end{array}$ & $\begin{array}{l}\text { UTHSCSA DI18-102 = } \\
\text { FMR } 17696=\text { CBS } \\
146934^{\top}\end{array}$ & LR701767 & LR701768 & $\begin{array}{l}\text { Illinois, U.S.A.; human } \\
\text { skin foot }\end{array}$ \\
\hline Spiromastigoides gypsea & CBS $134.77^{\top}$ & KT155798 & NG_063935 & California, U.S.A.; soil \\
\hline $\begin{array}{l}\text { Spiromastigoides } \\
\text { kosraensis }\end{array}$ & CBS $138267^{\top}$ & KP119633 & KP119646 & $\begin{array}{l}\text { Kosrae, Micronesia; } \\
\text { house dust }\end{array}$ \\
\hline $\begin{array}{l}\text { Spiromastigoides } \\
\text { pyramidalis }\end{array}$ & CBS $138269^{\top}$ & KP119636 & KP119649 & Australia; house dust \\
\hline $\begin{array}{l}\text { Spiromastigoides } \\
\text { sugiyamae }\end{array}$ & $\mathrm{JCM} 11276^{\top}$ & LN867608 & AB040680 & Japan; soil \\
\hline $\begin{array}{l}\text { Spiromastigoides } \\
\text { warcupii }\end{array}$ & CBS $576.63^{\top}$ & LN867609 & AB040679 & Australia; soil \\
\hline $\begin{array}{l}\text { Strongyloarthrosporum } \\
\text { capsulatus }\end{array}$ & CBS $143841^{\top}$ & LR760230 & LT906534 & Toledo, Spain; honey \\
\hline Trichophyton bullosum & CBS $363.35^{\top}$ & NR_144895 & NG_058191 & Unkown \\
\hline Uncinocarpus reesii & ATCC 34533 & MH861035 & AY176724 & Australia; feather \\
\hline
\end{tabular}

${ }^{1}$ ATCC: American Type Culture Collection, Virginia, USA; BCCM/MUCL: Mycothèque de I'Université Catholique de Louvain, Louvain-la-Neuve, Belgium; CBS: Culture collection of the Westerdijk Biodiversity Institute, Utrech, The Netherlands; CGMCC: China General Microbiological Culture Collection Center, Beijing, China; FMR: Facultat de Medicina, Reus, Spain; IFO: Institute for Fermentation Culture Collection, Osaka, Japan; JCM: Japan Collection of Microorganisms, Tsukuba, Japan; MCC: Microbial Culture Collection, Universite of Pune Campus Ganeshkhind, India; NFCCI: National Fungal Culture Collection of India, Maharastra, India; UAMH: University of Alberta Microfungus Collection and Herbarium, Alberta, Canada; UTHSC: Fungus Testing Laboratory, University of Texas Health Science Center at San Antonio, San Antonio, Texas, United States.

${ }^{2}$ Strains studied by us are indicated in bold.

${ }^{3}$ ITS: internal transcribed spacer region 1 and 2 including 5.8 S nrDNA; LSU: large subunit of the nrRNA gene.

TEx-type strain.

*Strain formerly assigned to Auxarthron thaxteri (a species synonymized with Malbranchea umbrina).

Table 2. Antifungal susceptibility of malbranchea-like strains studied. 


\begin{tabular}{|c|c|c|c|c|c|c|c|c|c|c|c|}
\hline \multirow[t]{2}{*}{ Taxon } & \multirow[t]{2}{*}{ Strain } & \multicolumn{10}{|c|}{ MIC/MEC ( $\mu \mathrm{g} / \mathrm{mL})$} \\
\hline & & AMB & FLC & VRC & ITC & PSC & AFG & CFG & MFG & TRB & $\begin{array}{l}\text { 5- } \\
\text { FC }\end{array}$ \\
\hline $\begin{array}{l}\text { Arachnomyces } \\
\text { bostrychodes }\end{array}$ & $\begin{array}{l}\text { FMR } \\
17685\end{array}$ & $>16$ & $>16$ & 2 & $>16$ & $>16$ & 0.03 & 0.06 & 0.06 & 0.5 & $>16$ \\
\hline $\begin{array}{l}\text { Currahmyces } \\
\text { sparsispora }\end{array}$ & $\begin{array}{l}\text { FMR } \\
17683\end{array}$ & $>16$ & $>16$ & 4 & $>16$ & 2 & $>16$ & 8 & $>16$ & $\leq 0.03$ & $>16$ \\
\hline \multirow[t]{2}{*}{$\begin{array}{l}\text { Malbranchea } \\
\text { albolutea }\end{array}$} & $\begin{array}{l}\text { FMR } \\
17679\end{array}$ & 8 & $>16$ & 1 & 1 & 0.25 & 0.03 & 0.06 & 0.06 & 0.25 & $>16$ \\
\hline & $\begin{array}{l}\text { FMR } \\
17689\end{array}$ & 8 & $>16$ & 2 & $>16$ & 1 & 0.12 & 0.06 & 0.25 & 0.25 & $>16$ \\
\hline \multirow[t]{2}{*}{ M. aurantiaca } & $\begin{array}{l}\text { FMR } \\
17682\end{array}$ & $>16$ & $>16$ & 1 & $>16$ & 0.25 & 0.12 & 1 & 0.12 & 4 & $>16$ \\
\hline & $\begin{array}{l}\text { FMR } \\
17688\end{array}$ & $>16$ & $>16$ & 2 & $>16$ & 0.5 & 0.5 & 0.06 & 1 & 2 & $>16$ \\
\hline \multirow[t]{2}{*}{ M. conjugata } & $\begin{array}{l}\text { FMR } \\
17697\end{array}$ & 8 & $>16$ & 0.5 & 0.25 & $\leq 0.03$ & 0.06 & 0.25 & 0.25 & 1 & $>16$ \\
\hline & $\begin{array}{l}\text { FMR } \\
17699\end{array}$ & $>16$ & $>16$ & 0.5 & 2 & 0.5 & 0.12 & 0.25 & 0.25 & 1 & $>16$ \\
\hline M. flocciformis & $\begin{array}{l}\text { FMR } \\
17698\end{array}$ & $>16$ & $>16$ & 1 & $>16$ & 0.5 & 0.12 & 0.03 & 0.12 & 0,5 & $>16$ \\
\hline M. gymnoascoidea & $\begin{array}{l}\text { FMR } \\
17681\end{array}$ & $>16$ & $>16$ & 8 & $>16$ & 1 & 0.03 & 0.03 & 0.12 & 0,5 & $>16$ \\
\hline M. multiseptata & $\begin{array}{l}\text { FMR } \\
17695\end{array}$ & 16 & $>16$ & 0.12 & 0.5 & 0.25 & 0.03 & 0.5 & 2 & 1 & $>16$ \\
\hline M. stricta & $\begin{array}{l}\text { FMR } \\
17680\end{array}$ & 8 & $>16$ & 0.25 & 0.12 & 0.12 & 0.03 & 0.25 & 0.25 & 0,12 & $>16$ \\
\hline \multirow[t]{4}{*}{ M. umbrina } & $\begin{array}{l}\text { FMR } \\
17693\end{array}$ & 4 & $>16$ & 2 & $>16$ & 0.5 & 0.06 & 0.06 & 0.12 & 0.25 & $>16$ \\
\hline & $\begin{array}{l}\text { FMR } \\
17694\end{array}$ & $>16$ & $>16$ & 4 & $>16$ & 0.5 & 0.06 & 1 & 0.12 & 0.25 & $>16$ \\
\hline & $\begin{array}{l}\text { FMR } \\
17700\end{array}$ & $>16$ & $>16$ & $>16$ & $>16$ & $>16$ & 0.5 & 1 & 0.5 & $>16$ & $>16$ \\
\hline & $\begin{array}{l}\text { FMR } \\
17701\end{array}$ & $>16$ & $>16$ & 4 & $>16$ & 0.12 & 0.03 & 0.03 & 0.03 & 0.12 & $>16$ \\
\hline M. zuffiana & $\begin{array}{l}\text { FMR } \\
17690\end{array}$ & $>16$ & $>16$ & 1 & $>16$ & 0.5 & 0.05 & 1 & 4 & 0.25 & $>16$ \\
\hline $\begin{array}{l}\text { Pseudomalbranchea } \\
\text { gemmata }\end{array}$ & $\begin{array}{l}\text { FMR } \\
17684\end{array}$ & 2 & $>16$ & 0.25 & 0.25 & 0.25 & 16 & 1 & 16 & $\leq 0.03$ & $>16$ \\
\hline \multirow[t]{2}{*}{$\begin{array}{l}\text { Spiromastigoides } \\
\text { geomyces }\end{array}$} & $\begin{array}{l}\text { FMR } \\
17686\end{array}$ & $>16$ & $>16$ & 2 & 1 & 1 & $>16$ & 2 & $>16$ & 0.12 & $>16$ \\
\hline & $\begin{array}{l}\text { FMR } \\
17696\end{array}$ & $>16$ & $>16$ & 2 & 0.5 & 0.5 & 2 & 16 & $>16$ & 0.06 & $>16$ \\
\hline
\end{tabular}


AMB, amphotericin B; FLC, fluconazole; VRC, voriconazole; ITC, itraconazole; PSC, posaconazole; AFG, anidulafungin; CFG, caspofungin; MFG, micafungin; TRB, terbinafine; 5-FC, 5-fluorocytosine. ND*: Non-determined due to no fungal growth under the conditions stablished by the CLSI protocol.

\section{Figures}
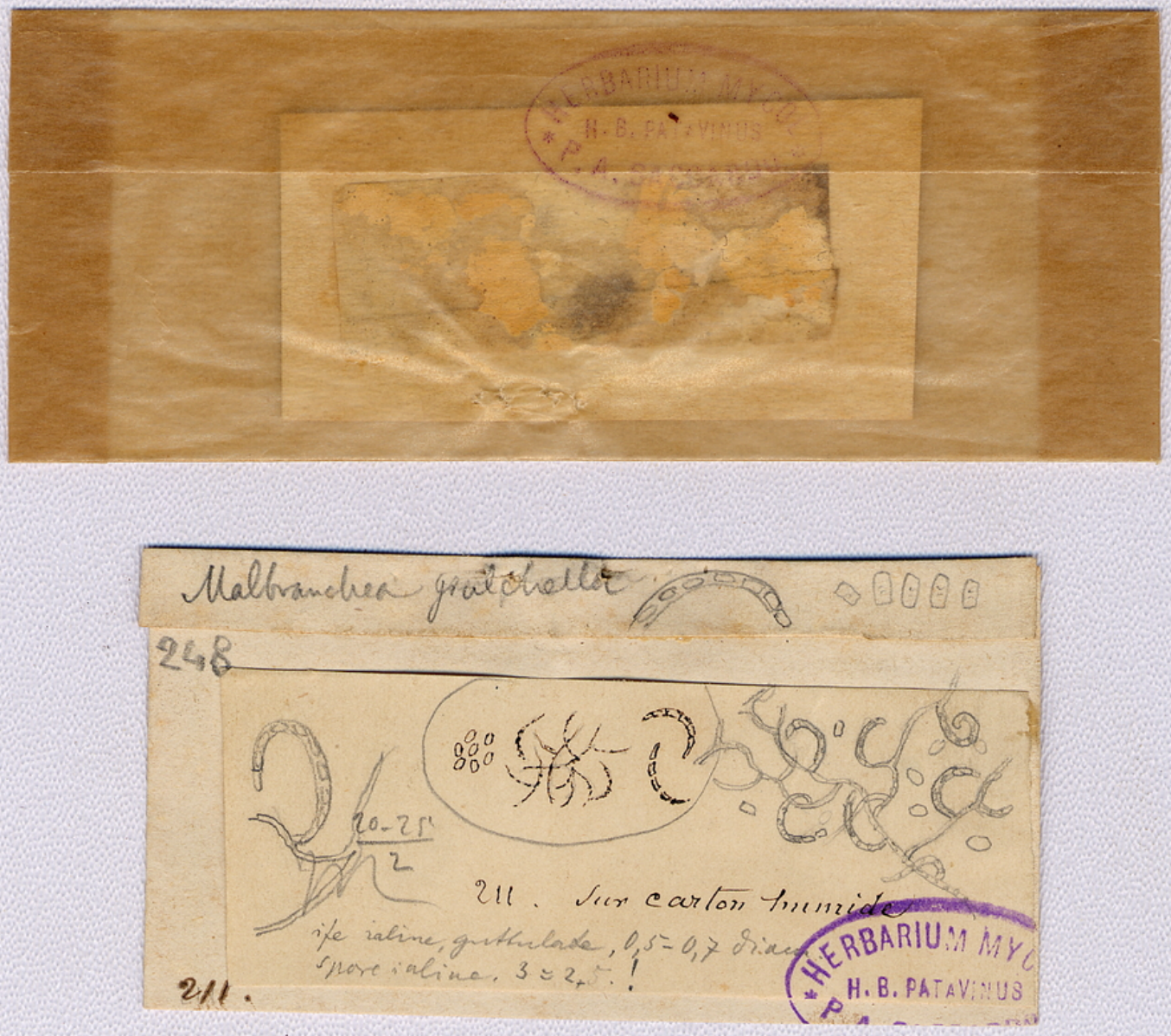

Malbranchea pulchella. Lacc. of Penr.
materiel TYPE

examinavit S.L. Hemehert

Hevedee, Belyiper, 7 nov. 1966

Figure 1 
Malbranchea pulchella Sacc. \& Penzig. Holotype and lectotype. Black ink drawings by A. Malbranche, and pencil drawings by P. A. Saccardo (credits: Rosella Marcucci, erbario micologico di Pier Andrea Saccardo, Università di Padova, Italy).

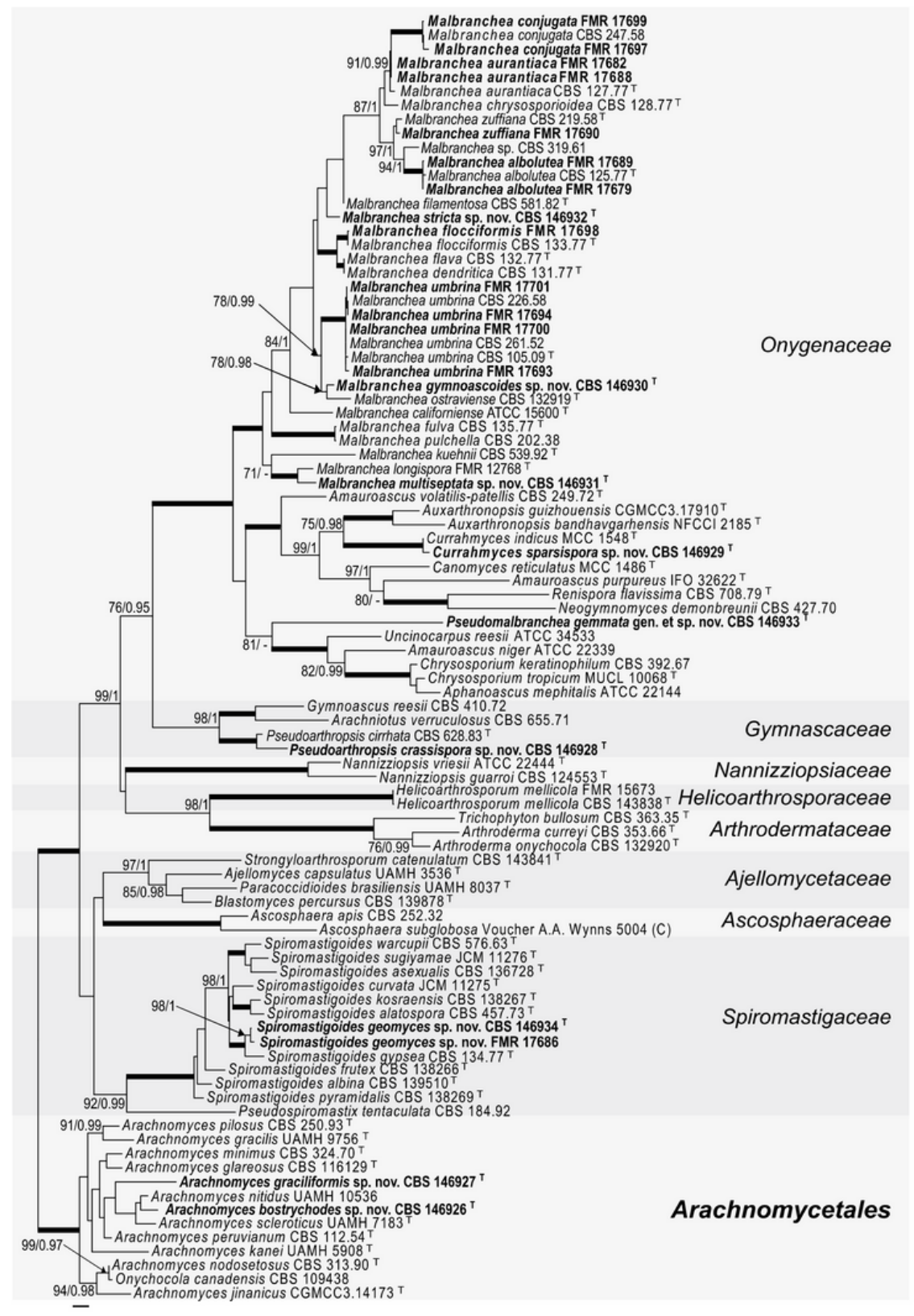

\section{Figure 2}

ML phylogenetic tree based on the analysis of ITS-LSU nucleotide sequences for the twenty-two clinical fungi from the USA. Bootstrap support values/Bayesian posterior probability scores of 70/0.95 and higher are indicated on the nodes. $T$ = ex type. Fully supported branched (100\% BS /1 PP) are indicated in bold. Strains identified by us are in bold. Arachnomyces spp. were chosen as out-group. The sequences used in this analysis are in Table 1 

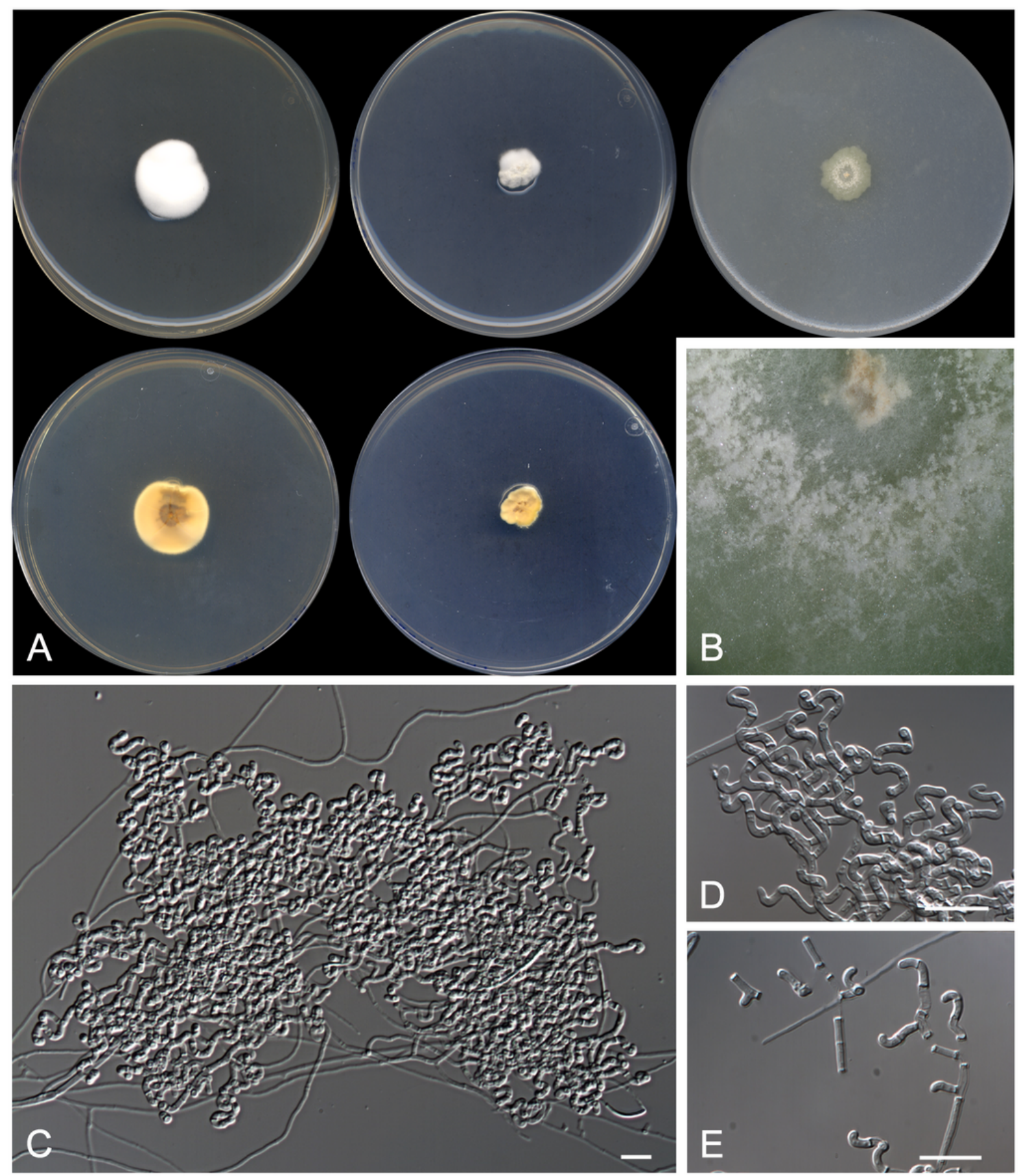

Figure 3

Arachnomyces bostrychodes CBS $146926 \mathrm{~T}$. A. Colonies on PYE, PDA and OA after $14 \mathrm{~d}$ at $25^{\circ} \mathrm{C}$, from left to right (top row, surface; bottom row, reverse). B. Detail of the colony on OA. C, D. Sinuous, contorted to coiled fertile hyphae. E. Arthroconidia. Scale bar $=10 \mu \mathrm{m}$. 

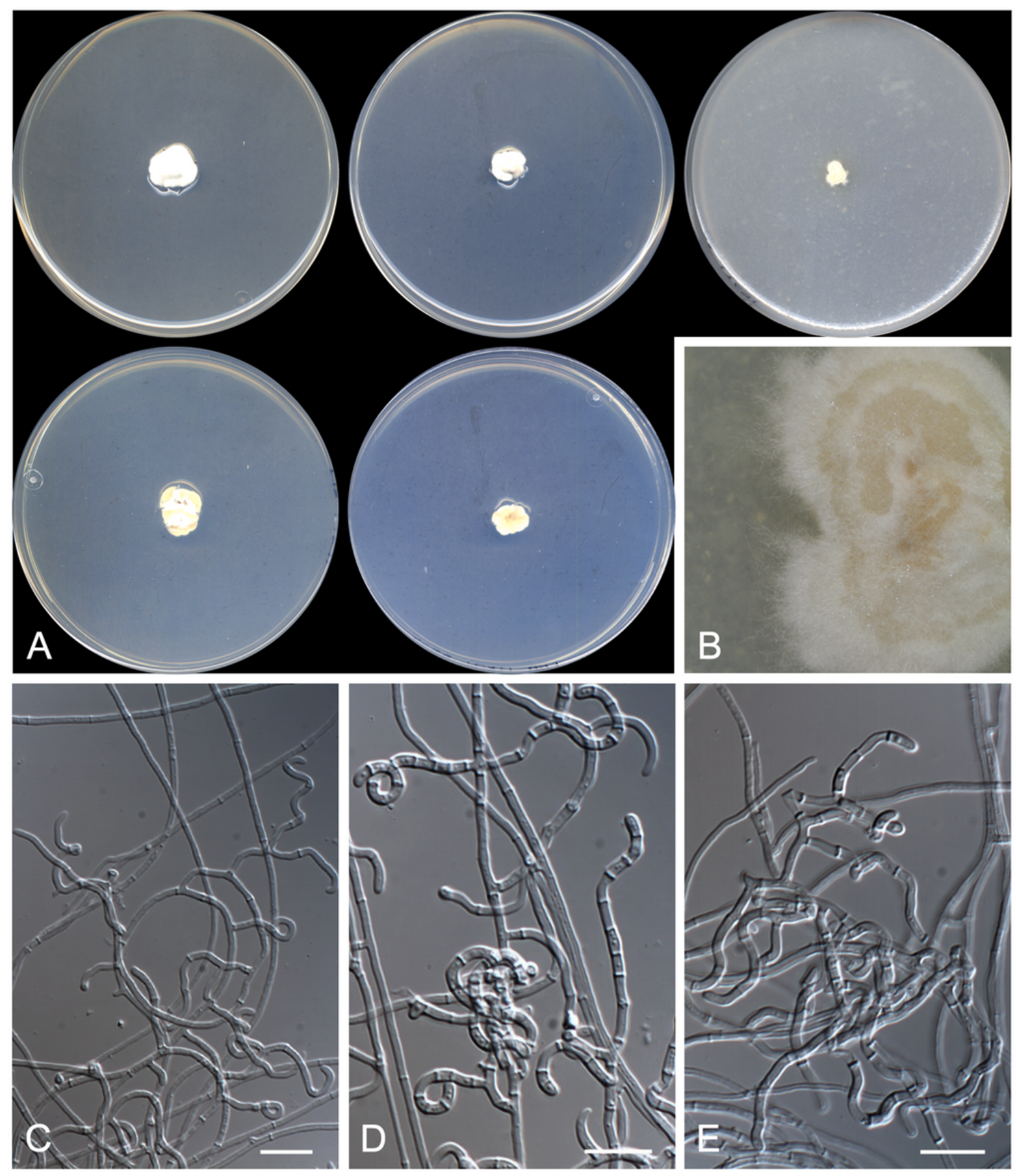

Figure 4

Arachnomyces graciliformis CBS $146927 \mathrm{~T}$. A. Colonies on PYE, PDA and OA after $14 \mathrm{~d}$ at $25^{\circ} \mathrm{C}$, from left to right (top row, surface; bottom row, reverse). B. Detail of the colony on OA. C-E. Contorted, apically coiled fertile hyphae bearing arthroconidia. Scale bar $=10 \mu \mathrm{m}$. 

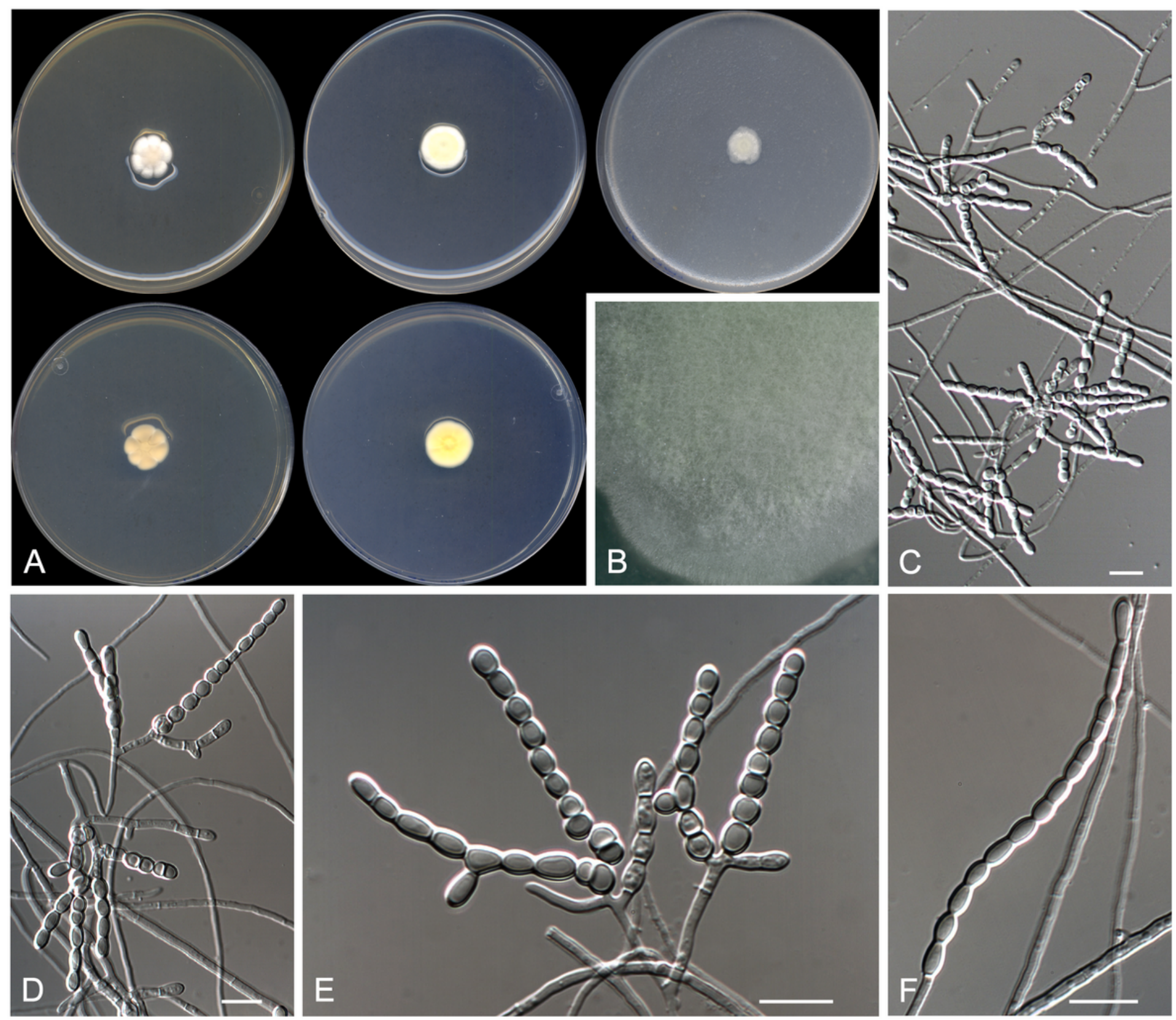

\section{Figure 5}

Pseudoarthropsis crassispora CBS $146928 \mathrm{~T}$. A. Colonies on PYE, PDA and OA after $14 \mathrm{~d}$ at $25^{\circ} \mathrm{C}$, from left to right (top row, surface; bottom row, reverse). B. Detail of the colony on OA. C-E. Bi- to trichotomously-branched fertile hyphae. F. A large chain of holoarthric conidia. Scale bar $=10 \mu \mathrm{m}$. 

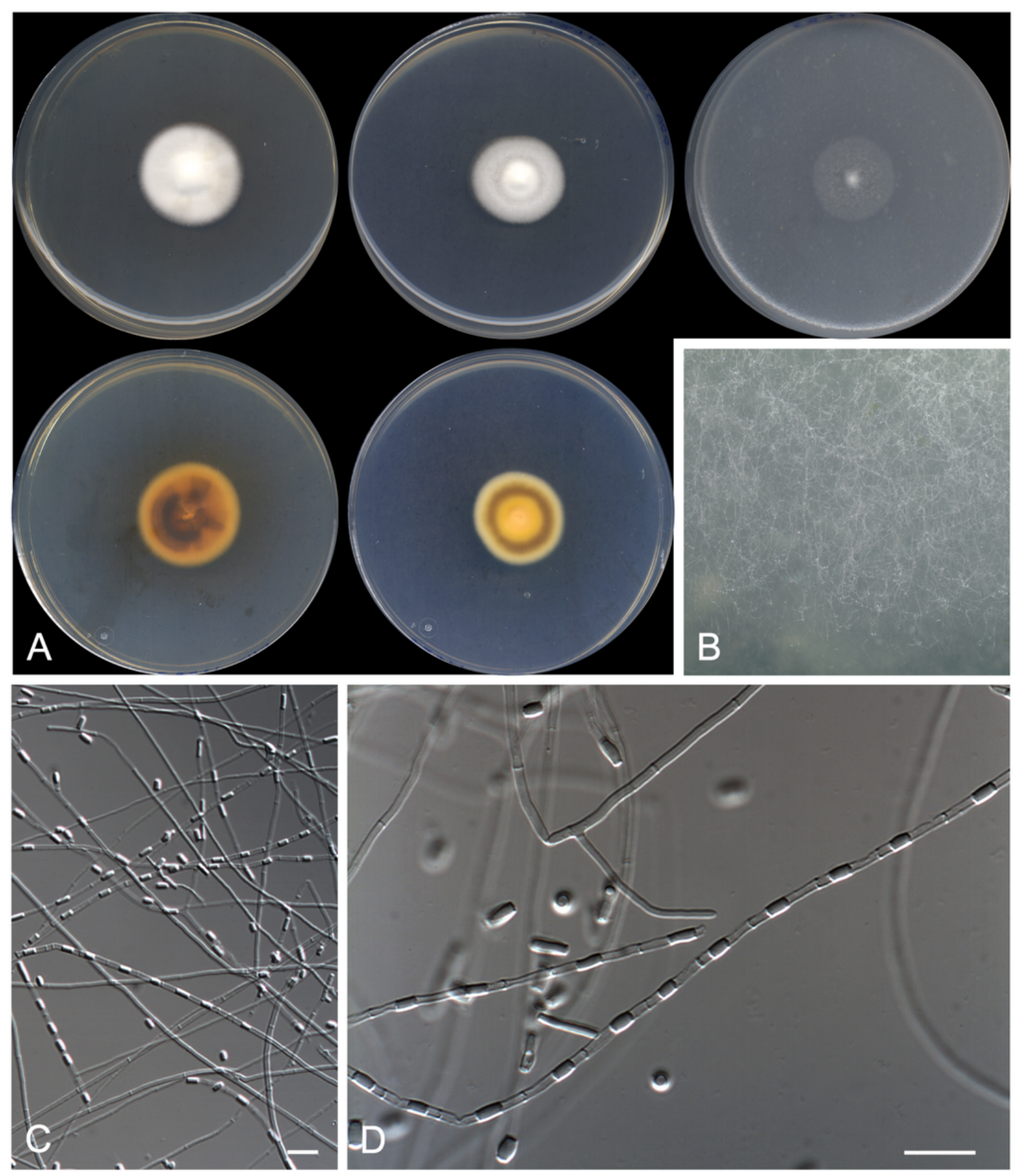

\section{Figure 6}

Currahmyces sparsispora CBS 146929 T. A. Colonies on PYE, PDA and OA after $14 \mathrm{~d}$ at $25^{\circ} \mathrm{C}$, from left to right (top row, surface; bottom row, reverse). B. Detail of the colony on OA. C-D. Intercalary arthroconidia along the fertile hyphae. Scale bar $=10 \mu \mathrm{m}$. 

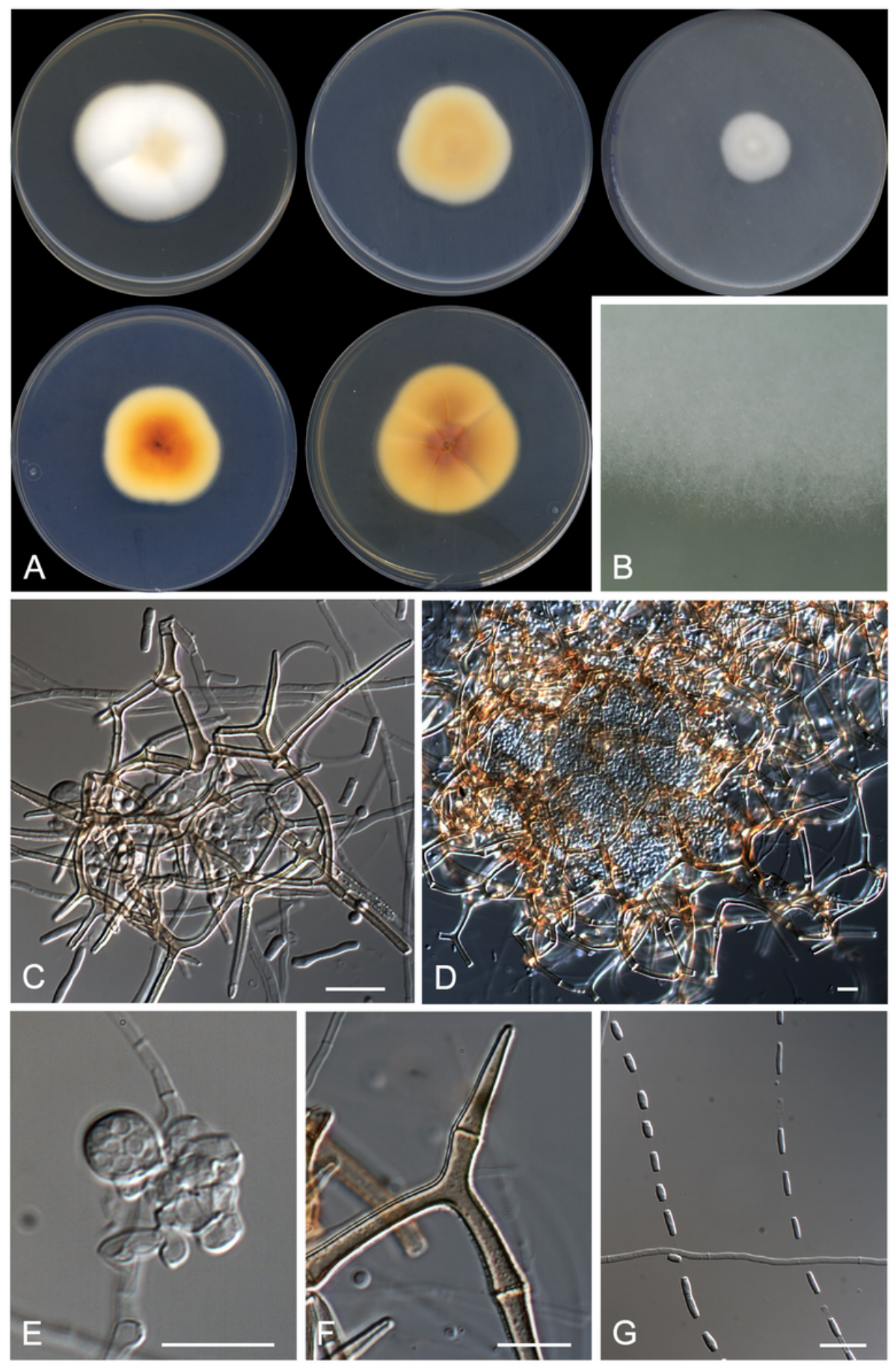

Figure 7

Malbranchea gymnoascoides CBS $146930 \mathrm{~T}$. A. Colonies on PYE, PDA and OA after $14 \mathrm{~d}$ at $25^{\circ} \mathrm{C}$, from left to right (top row, surface; bottom row, reverse). B. Detail of the colony on OA. C-D. Young and mature ascomata. E. Young ascus on fertile hyphae. F. Peridial spine-like appendage. G. Intercalary arthroconidia along the fertile hyphae. Scale bar $=10 \mu \mathrm{m}$. 

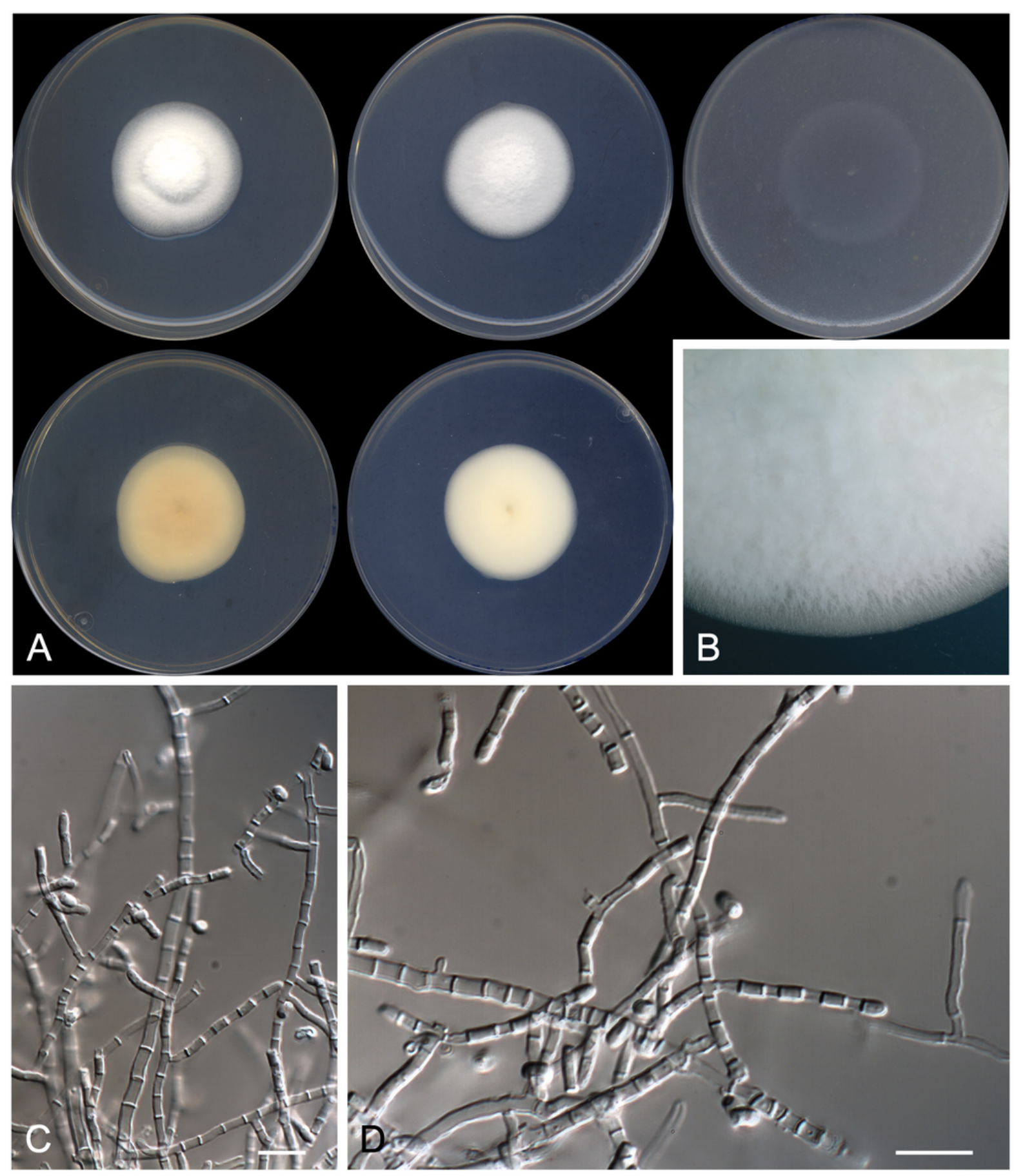

\section{Figure 8}

Malbranchea multiseptata CBS $146931 \mathrm{~T}$. A. Colonies on PYE, PDA and OA after $14 \mathrm{~d}$ at $25^{\circ} \mathrm{C}$, from left to right (top row, surface; bottom row, reverse). B. Detail of the colony on PDA. C-D. Highly septate fertile hyphae and arthroconidia. Scale bar $=10 \mu \mathrm{m}$. 

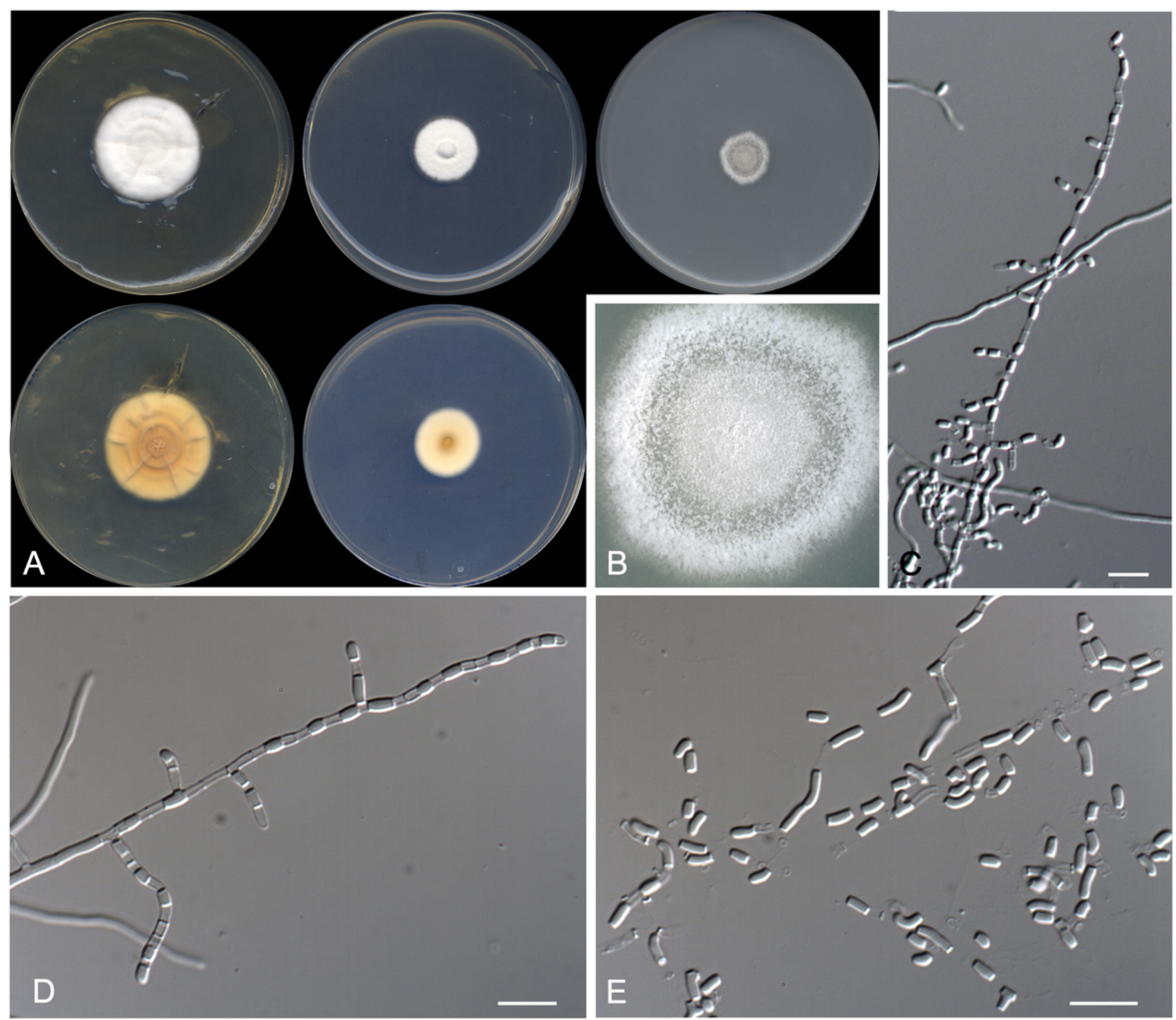

\section{Figure 9}

Malbranchea stricta CBS 146932 T. A. Colonies on PYE, PDA and OA after $14 \mathrm{~d}$ at $25^{\circ} \mathrm{C}$, from left to right (top row, surface; bottom row, reverse). B. Detail of the colony on OA. C-E. Alternate arthroconidia on primary hyphae and lateral branches. Scale bar $=10 \mu \mathrm{m}$. 

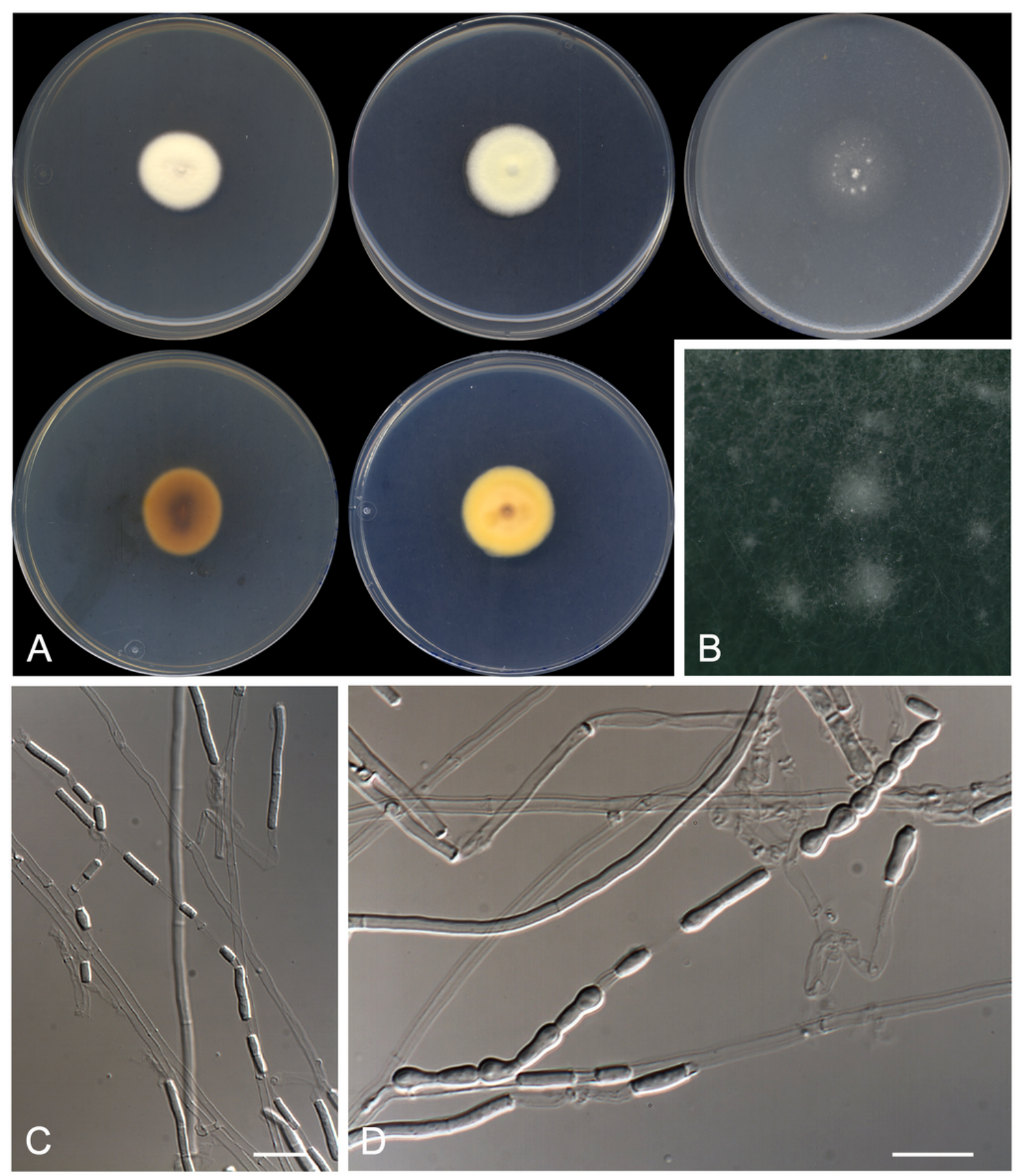

Figure 10

Pseudomalbranchea gemmata CBS $146933 \mathrm{~T}$. A. Colonies on PYE, PDA and OA after $14 \mathrm{~d}$ at $25^{\circ} \mathrm{C}$, from left to right (top row, surface; bottom row, reverse). B. Detail of the colony on OA. C-D. Large, intercalary, irregularly-shaped arthroconidia disposed singly or in chains along the fertile hyphae. Scale bar $=10 \mu \mathrm{m}$. 

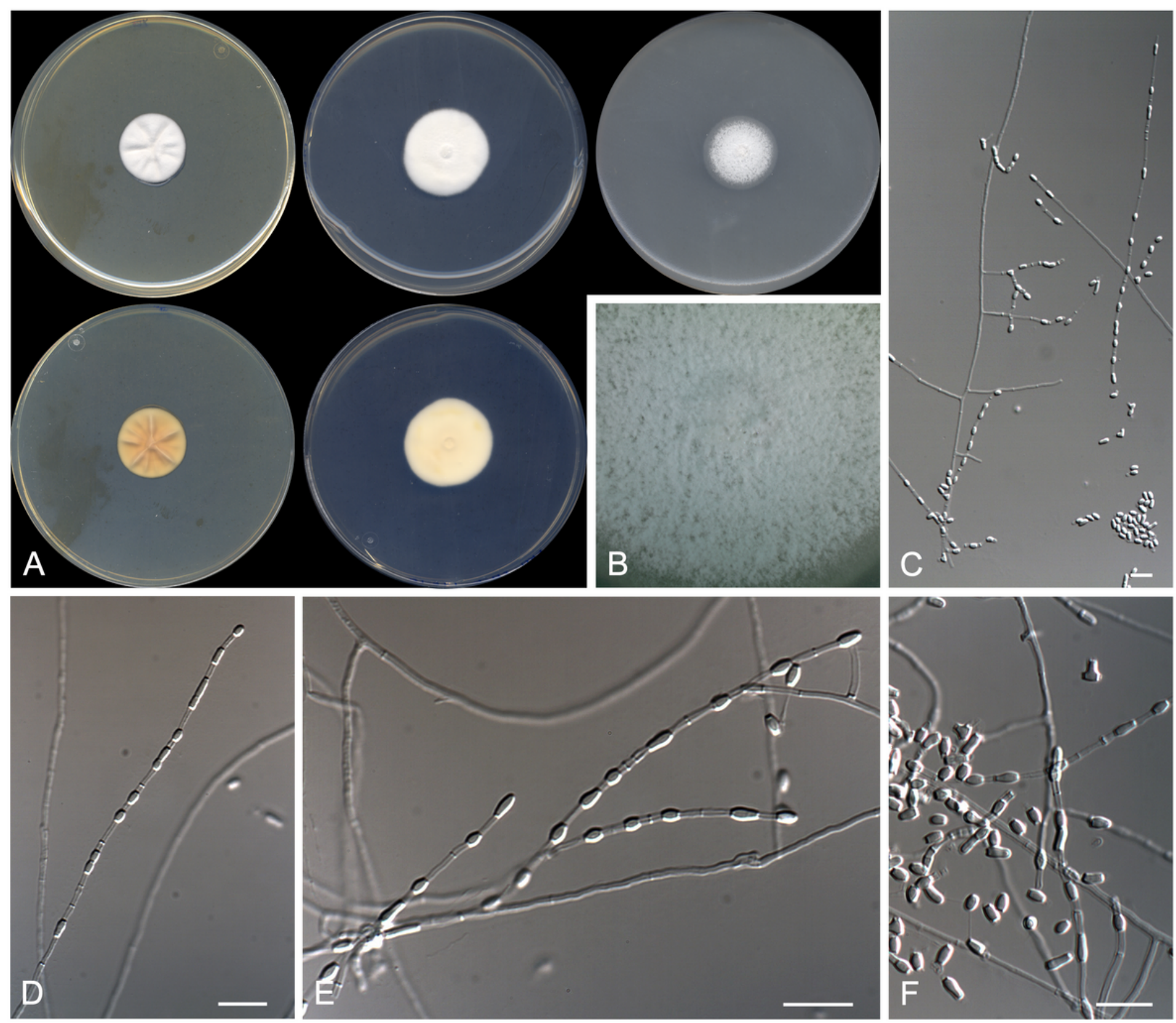

\section{Figure 11}

Spiromastigoides geomyces CBS $146934 \mathrm{~T}$. A. Colonies on PYE, PDA and OA after $14 \mathrm{~d}$ at $25^{\circ} \mathrm{C}$, from left to right (top row, surface; bottom row, reverse). B. Detail of the colony on OA. C. Fertile lateral branches mimicking Geomyces spp. conidiophores. D-E. Fertile hyphae with intercalary, barrel-shaped arthroconidia. F. Morphological diversity of arthroconidia. Scale bar $=10 \mu \mathrm{m}$. 